\title{
On the characteristics and climate effects of HV-WCP events over the Kuroshio SST front during wintertime
}

\author{
Haokun Bai ${ }^{1} \cdot$ Haibo Hu ${ }^{1,2}\left(\right.$ D $\cdot$ William Perrie ${ }^{3} \cdot$ Ning Zhang $^{1}$ \\ Received: 16 March 2020 / Accepted: 9 July 2020 / Published online: 22 July 2020 \\ (c) The Author(s) 2020
}

\begin{abstract}
Neglected High-frequency Variability events of the sea surface Wind Coupled with Precipitation (HV-WCP) events are revealed over the Kuroshio Sea Surface Temperature (SST) front in the East China Sea (ECS) during wintertime. This phenomenon is characterized as modulation events of the surface wind directions, whereby the southerly anomaly changes into a northwest anomaly, accompanied with increasing wind speed, and coupled with decreasing precipitation from morning to night on the day with the peak variability. The events are associated with significant climate effects on the rainfall anomaly over southeastern China and adjacent ocean areas of the ECS. To sustain these events, the large-scale circulation needs to exhibit declines in the upstream monsoon and weakening vertical mixing in the planetary boundary layer (PBL). The Kuroshio thermal effect on the underlying atmosphere becomes prominent due to weakening vertical mixing, which results in pronounced PBL height gradient over the Kuroshio SST front. More plentiful moisture transported from PBL to the free atmosphere, generates the initialization of rainfall and the cyclone anomaly. Meanwhile, the latent heat releasing caused by this precipitation forces positive vorticity anomaly within the PBL, which again strengthens the cyclone and the upward moisture transport. Therefore, a complement between local circulation and rainfall is developed over the Kuroshio region. Due to the significant effect of the Kuroshio SST front on the PBL structure, the HV-WCP intensity is able to maintain its strength over the Kuroshio region. However, because of the northwestern background monsoon, the HV-WCP events vanish quickly when the coupled system moves out of Kuroshio SST frontal region.
\end{abstract}

Keywords Atmospheric high-frequency variability $\cdot$ Kuroshio SST front $\cdot$ Planetary boundary layer $\cdot$ Precipitation

\section{Introduction}

In midlatitudes, the oceanic fronts with large horizontal gradients in sea surface temperature (SST) have been proved the essential areas where the forcing of the ocean onto atmosphere is pronounced (Chelton et al. 2004; Tokinaga et al. 2005, 2006; Minobe et al. 2008; Small et al. 2008; Bryan et al. 2010; Chelton and Xie 2010). Most previous studies about the atmospheric variability response to the SST front focused on the climate variability and low-frequency atmospheric variability (e.g. decadal variability, interannual variability and intraseasonal variability) (Nakamura et al. 1997; Nakamura and Kazmin 2003; Feliks et al. 2004, 2007; Wang et al. 2019; Chen et al. 2019a). However, studies on the highfrequency atmospheric variability (e.g. the synoptic-scale variability and diurnal variability), especially the diurnal variability over SST front, are much less common.

Indeed, the high-frequency atmospheric variability is the one of the most basic features of the earth's atmosphere 
motions, which is crucial for short-time weather forecasting and play an important role in dynamics of the global climate, mainly including the diurnal variability events ( $24 \mathrm{~h}$ ) and synoptic-scale activities (2-7 days). Therein, the diurnal variability is the pronounced signals of climate system, which is mainly driven by diurnal variation of the solar radiation (Wallace 1975; Garreaud and Wallace 1997; Sui et al. 1998; Yang and Slingo 2001; Sorooshian et al. 2002). The synoptic-scale disturbances can be seen evidently from the daily weather map, characterized with 2-7 days transient activity period and propagate with two waveguides (Hoskins and Hodges 2002; Nakamura et al. 2002). Due to differing underlying surface conditions and physical processes, the diurnal and synoptic-scale variations of meteorological variables vary with regions and seasons (Carillo et al. 2000; Nakamura and Shimpo 2004; Yang and Smith 2006).

Besides the temperature diurnal cycle determined directly by solar radiation, the related issues of precipitation and local circulations diurnal variations have always been the hotspots of regional climate research (Bergman and Salby 1996; Dai and Deser 1999; Dai and Trenberth 2004). Typical events of wind diurnal variabilities are the sea-land breeze and mountain-valley breeze, which are subject to the modulation of mountain-valley and land-sea differential heating (Hamilton 1980; Krishnamurti et al. 2000; Ciesielski and Johnson 2008). Furthermore, it is also apparent that diurnal local circulations are influenced by the large-scale atmospheric conditions (Huang et al. 2010). The diurnal variation of precipitation is an essential reaction of regional climate resulting from the comprehensive influence of atmospheric thermal and dynamic processes, which involves the multiinteractions of land-atmosphere, sea-atmosphere, sea-land and mountain-valleys at different scales (Neumann 1951; Kraus 1963; Wolyn and Mckee 1994; Higgins et al. 1997; Chen et al. 2015). There is an apparent regional difference with the diurnal rainfall variations due to the complex underlying surface distributions and different surface forcing ( $\mathrm{Yu}$ et al. 2007a, b, 2009; Li et al. 2008; Zhou et al. 2008; Bao et al. 2011). In monsoon regions, the low-level winds have been proven to be related to monsoon dynamics and coupled with the regional precipitation (Ramage 1952; Wai et al. 1996; Fujinami and Yasunari 2001; Terao et al. 2006; Guan et al. 2019). According to amplitude, peak time, and phase propagation characteristics of diurnal precipitation, Kikuchi and Wang (2008) identified three regimes diurnal precipitation in the global tropics, including the moderate amplitude and an early morning peak in the oceanic regime, a large amplitude and an afternoon peak in the continental regime, and the large amplitude and prominent phase propagation in the coastal regime. Chen et al. (2013) demonstrated that the low-level wind averaged over East Asia is strongest during late night or early morning hours, which is inferred as a diurnal monsoon variability. Such nocturnal acceleration occurs frequently when monsoon flow becomes active. It usually develops in the warm region south of the frontal zone, and is closely related to the ageostrophic flow. Using an idealized land-sea-breeze model, Du and Rotunno (2015) found that the low-level diurnal wind signals propagate eastward off the southeast coast of China, whereas diurnal wind variations off the northeast coast are nearly in phase.

To explain the diurnal variations of the low-level wind, at least two primary mechanisms have been put forward. One is the initial oscillation mechanism (Blackadar 1957) and the other is the thermal wind adjustment mechanism (Holton 1967). Based on these two mechanisms, the diurnal oscillations in the ageostrophic wind vector contribute more diurnal variabilities to the low-level wind, when the initial oscillation effect is predominant (Blackadar 1957; Van de Wiel et al. 2010; Shapiro and Fedorovich 2010). However, the thermal wind adjustment mechanism provides a better explanation of the diurnal variabilities of the geostrophic wind (Holton 1967; Bonner and Paegle 1970; Du and Rotunno 2014). Over East Asia, many studies have shown that the initial oscillation mechanism is more effective to explain the diurnal variabilities of the low-level wind and the coupled precipitation events (Chen et al. 2009, 2013; Du et al. 2012; Du and Rotunno 2014, 2018). Furthermore, the diurnal variabilities of low-level wind and precipitation are modulated by the large-scale atmospheric background. Xue et al. (2018) found that the low-level ageostrophic winds exhibit diurnal cycles with clockwise rotations due to the inertial oscillation mechanism over China, whereby wind directions and magnitudes depend on the background geostrophic monsoon flows. They also indicated that the lowlevel ageostrophic winds control the net moisture flux into the rain bands of the Meiyu front and cause the anomaly variabilities in the diurnal precipitation.

For the diurnal variability, the previous studies mostly focus on local circulation and precipitation events over land or coastal areas. This is due to the most basic properties of the ocean, the great heat capacity and the slow changing. These properties make the diurnal variation effect of the solar radiation on the ocean much weaker than that on the land. Therefore, most previous studies about the SST front effects on the atmosphere focused on the longer time scales, such as climate variability and low-frequency atmospheric variability (e.g. decadal variability, interannual variability and intraseasonal variability) (Nakamura et al. 1997; Nakamura and Kazmin 2003; Feliks et al. 2004, 2007; Wang et al. 2019; Chen et al. 2019a). However, over oceanic fronts with large horizontal SST gradients, the heat fluxes have significant differences over the warm flank compared to the cold flank, which is similar to the land-sea breeze, in the sense of a localized circulation driven by the diurnal varying differential heating between land and ocean. The diurnal atmospheric 
variability over SST front could play an important role in regional weather and climate system. For the synopticscale disturbances, mostly previous studies pay attention on the storm track (Nakamura et al. 1997, 2004; Nakamura and Kazmin 2003; Wang et al. 2019; Chen et al. 2019a), which is the most active and clustered area of the synoptic-scale transient eddy activities (Blackmon 1976; Hoskins and Hodges 2002). However, the specific evolution of individual synoptic-scale activity does not get much enough attention. Furthermore, different from the land-sea breeze over coastal regions, there is no inversion of the temperature gradient on both sides of the SST front in the morning and evening, resulting in the barocline-thermal conditions cannot be formed as the land-sea breeze. Nevertheless, the observations (Figs. 1, 2, 3, 4, 5) showed that the high-frequency variation events mainly manifested as the diurnal variability exist over Kuroshio SST front. Thus, this study focuses on the mechanism of the this high-frequency event over Kuroshio SST front. In addition, high-frequency atmospheric events will lead to significant precipitation anomalies both locally and over southeastern China, which has great significance for the study and prediction of weather and short-term climate.

Over SST front areas, the near-surface wind within the planetary boundary layer (PBL) can be exerted by the sea level pressure (SLP) adjustment mechanism (Lindzen and Nigam 1987; Small et al. 2003, 2005; Song et al. 2006; Shimada and Kawamura 2008) and vertical mixing mechanism (Wallace et al. 1989; Hayes et al. 1989; Hashizume et al. 2002; Skyllingstad et al. 2007). Moreover, recent studies have demonstrated that the climatological effects of SST fronts may extend into the free atmosphere and provide an anchor for rain bands by triggering deep cumulus convection along the warm current (Minobe et al. 2008; Tokinaga et al. 2006; Kuwano-Yoshida et al. 2010; Xu et al. 2011; Xu and $\mathrm{Xu}$ 2015). In the East China Sea (ECS), a conspicuous small-scale SST front can lead to a remarkable heat discharge accompanying the Kuroshio current, which has been proven to have a remarkable impact on the regional climate and weather system over East Asia (Small et al. 2008; Shimada and Kawamura 2008; Bryan et al. 2010; Chelton and Xie 2010; Xu et al. 2011; Xu and Xu 2015; Wang et al. 2019;
Fig. 1 The diurnal standard deviation (STD) of $10 \mathrm{~m}$ wind speed (shadings) (a, b) and wind direction (shadings) (c, d), and the SST field (contours; ${ }^{\circ} \mathrm{C}$ ) in CFSR data during the winters of 1986-2016. a-d Show the STD results within 1-day and 7-days, respectively
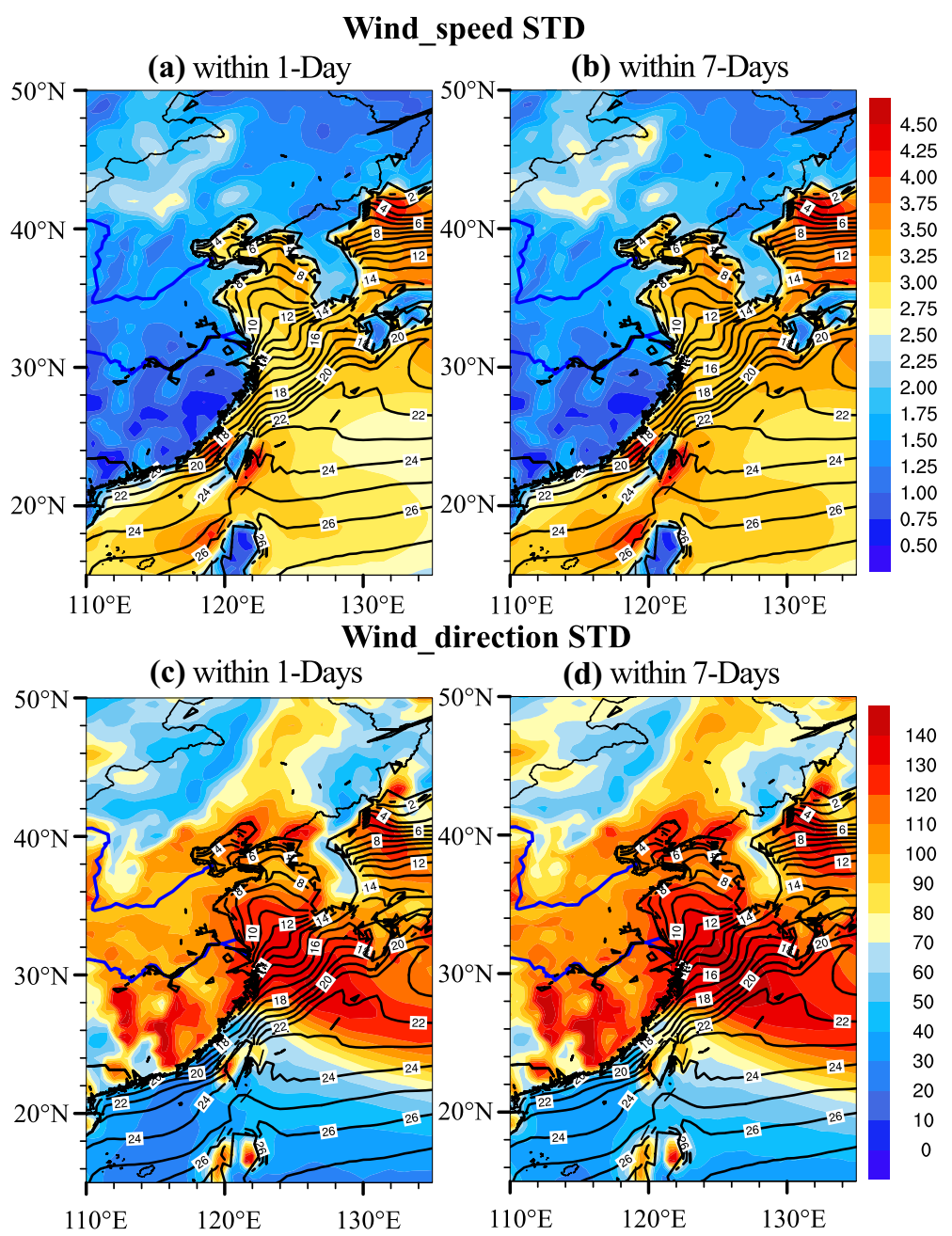
wind speed diurnal STD (a) CCMP

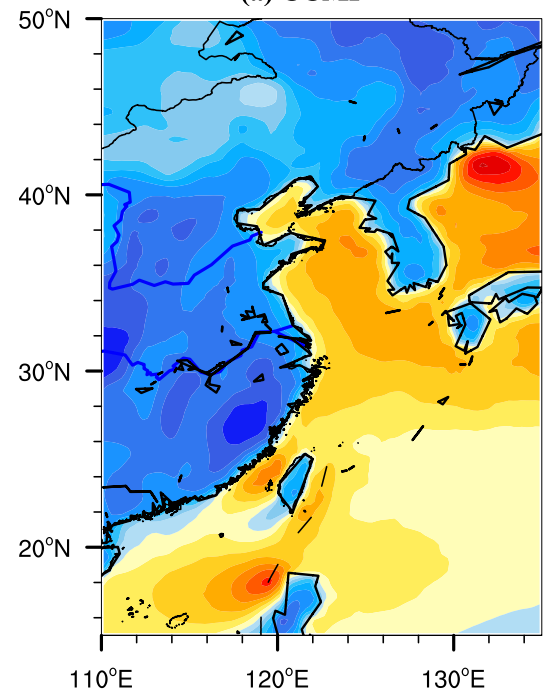

\section{(b) CFSR}

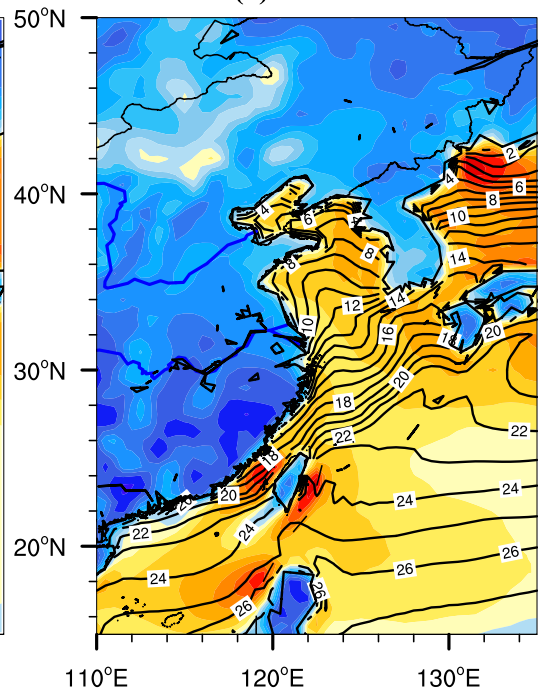

(c) ERA5

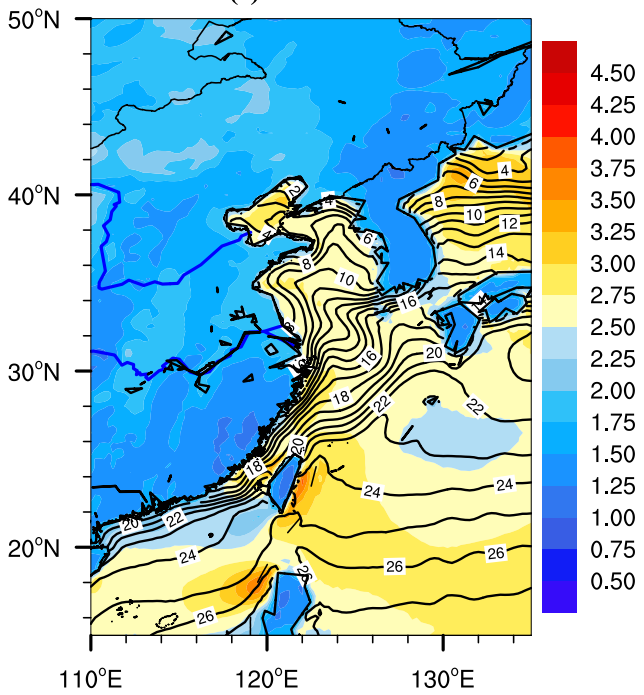

wind direction diurnal STD (e) CFSR

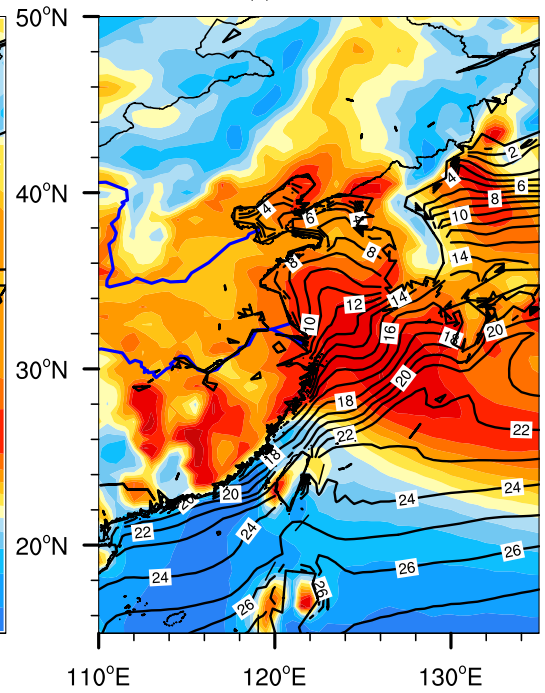

(f) ERA5

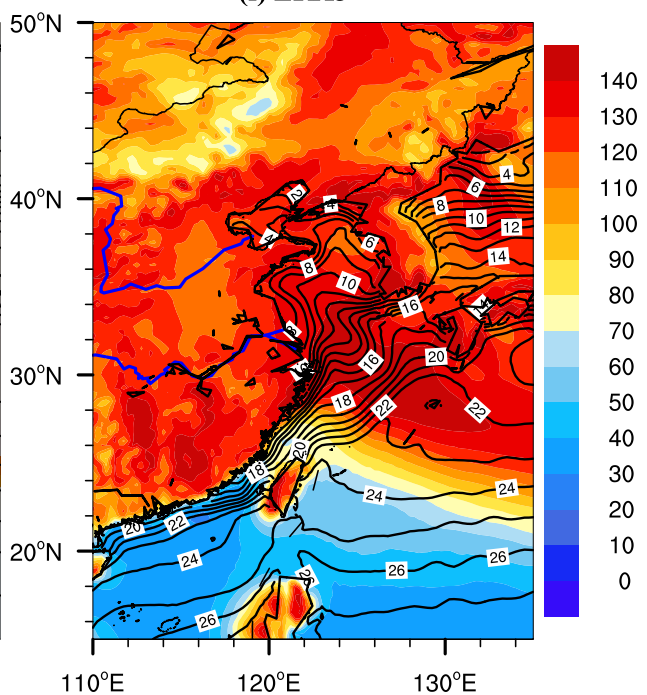

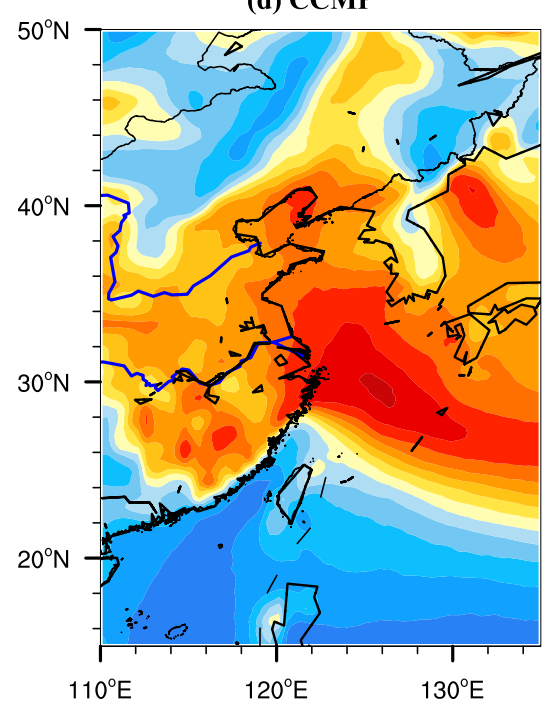

STD results and the SST field (contours; ${ }^{\circ} \mathrm{C}$ ) in CFSR data; $\mathbf{c}, \mathbf{f}$ show the STD results and the SST field (contours; ${ }^{\circ} \mathrm{C}$ ) in ERA5 data
Fig. 2 The high-frequency standard deviation (STD) of wind speed (shadings) a-c wind direction (shadings), $\mathbf{d}-\mathbf{f}$ during the winters of 1986-2016. a, d Show the STD results in CCMP data; b, e show the
Chen et al. 2019a). However, as mentioned above, there are fewer studies regarding the effects of high-frequency atmospheric variabilities over the Kuroshio SST front. The study of Xu and Xu (2015) explored the different low-level synoptic-scale wind patterns over Kuroshio SST front. Using a linearized model, Schneider and Qiu (2015) suggested that the boundary layer response to the SST front occurs on a short time-scale. The response time is governed by three processes: a fast thermodynamic adjustment of about 1 day, a dynamic adjustment to large-scale divergence on 2 days, and a slower radiative adjustment of 4 days. Bai et al. (2019) also proved this high-frequency events of the marine atmospheric boundary layer (MABL) response to the Kuroshio SST front. The study further revealed that the prevailing wind events, with different near-surface wind directions, have different duration times. These events show obvious high-frequency variabilities of the surface wind speed when its duration time is about 18-72 $\mathrm{h}$; however, the occurrence conditions and the specific characteristics of the high-frequency variability events are not clear yet. Moreover, some studies have proved the SST front affects the regional precipitation revolution by high-frequency atmospheric variability (Xu et al. 2018; 
Hirata et al. 2019). Nevertheless, there remain several questions. Are the high-frequency atmospheric variability events significant with respect to climatological statistical analysis, or only some kind of random synoptic-scale weather activities? What is the mechanism of the high-frequency variability events over the Kuroshio SST front? Why does the special high-frequency variability occur just over the Kuroshio SST front? What about the evolution and climate effects of these high-frequency variability events over the Kuroshio SST front? To date, these questions have not been well solved.

Therefore, this present study is designed to clarify the role of high-frequency variability in the atmospheric events over the Kuroshio SST front in the ECS during wintertime. A primary focus is the atmospheric high-frequency variability, with the combined effects of the winter monsoon and the Kuroshio SST front. The paper is presented as follows. Section 2 describes the data and method in the study. The characteristics of the high-frequency atmospheric variability events and the associated climate effects over Kuroshio SST front are analyzed in Sect. 3. Section 4 explores the mechanism of the formation of the high-frequency atmospheric variability events over the SST front. Finally, the summary and discussion are presented in Sect. 5.

\section{Data and methods}

In this study, we used Climate Forecast System Reanalysis (CFSR) 6-hourly Products during the wintertime (December, January, February) of 1979-2010, Climate Forecast System Version 2 (CFSv2) 6-hourly products during the wintertime of 2011-2016, the fifth generation European Center for Medium-Range Weather Forecasts (ECMWF) Atmospheric Reanalysis (ERA5) hourly Products during wintertime of 1979-2016 and the Cross-Calibrated, MultiPlatform (CCMP) Version 2 6-hourly wind field products during wintertime of 1987-2016 to analyze the atmospheric high-frequency variability over the Kuroshio SST front.

The National Centers for Environmental Prediction (NCEP) CFSR was initially completed over the 31-year period from 1979 to 2009 and has been extended to March 2011 (Saha et al. 2014). CFSR is initialized 4 times per day $(0000,0600,1200$, and 1800 UTC), and the 6-hourly atmospheric, oceanic and land surface analyzed products are available at various horizontal resolutions. CFSR is the first dataset from NCEP that assimilates satellite emitters directly into its global reanalysis product so that CFSR can provide a more detailed and accurate description of the atmosphere and the ocean. Compared to other global reanalysis data, CFSR spatial resolution has been greatly improved. CFSR considers the coupling of the atmosphere and the ocean, adds a sea-ice model, and considers changes of $\mathrm{CO}_{2}$, aerosols and other trace gases since 1979. NCEP upgraded their operational CFS to version 2 on March 30, 2011 (Saha et al. 2011). This is the same model that was used to create the CFSR, and the purpose of this dataset is to extend CFSR. The 6-hourly atmospheric, oceanic and land surface analyzed products and forecasts are archived beginning with January 1, 2011 as an extension of CFSR. Here, to simplify description, we hereafter use CFSR to represent the CFSR data from 1979 to 2010 and the CFSv2 data from 2011 to 2016.

The ERA5 is the latest climate reanalysis produced by ECMWF, providing hourly data on many atmospheric, landsurface and sea-state parameters together with estimates of uncertainty. ERA5 combines model data with observations from across the world into a globally complete and consistent dataset using the laws of physics. Using the 4D-Var data assimilation method in Cycle 41R2 of ECMWF's Integrated Forecast System (IFS), it takes account of the exact timing of the observations and model evolution within the assimilation window. This hourly output resolution is quite an improvement with respect to the last generation ECMWF's reanalysis product (ERA-interim), and provides a more detailed evolution of particular weather events (https://confluence .ecmwf.int//pages/viewpage. action?pageId=74764925). ERA5 hourly data are available in the Climate Data Store on regular latitude-longitude grids at $0.25^{\circ} \times 0.25^{\circ}$ resolution, with atmospheric parameters on 37 pressure levels from 1979 to present.

The Version-2 CCMP wind field product is developed by the Physical Oceanography Distributed Active Archive Center (PO. DAAC) of National Aeronautics and Space Administration (NASA). It combines inter-calibrated satellite data from numerous radiometers and scatterometers and in-situ data from moored buoys, including Version-7 Remote Sensing Systems (RSS), Special Sensor Microwave Imager (SSM/I), Tropical Rainfall Measuring Mission Microwave Imager (TMI), the Advanced Microwave Scanning Radiometer for Earth Observing System (AMSR-E), Sea Winds on Quick Scatterometer (Quik SCAT), Sea Winds on the second Japanese Advanced Earth Observing Satellite (ADEOSII) and other data using variational methods. The CCMP wind data are available with $0.25^{\circ} \times 0.25^{\circ}$ resolution from $78.375^{\circ} \mathrm{S}$ to $78.375^{\circ} \mathrm{N}$ and $179.875^{\circ} \mathrm{W}$ to $179.875^{\circ} \mathrm{E}$, at 6 -h intervals in time from July 1987 to the present. The CCMP wind is widely recognized because of its high spatial resolution, accuracy and the other aspects related to its construction.

The CFSR is available at 6-h intervals with an approximately horizontal grid spacing of $0.5^{\circ}$ and 37 vertical pressure levels from 1000 to $1 \mathrm{hPa}$; the ERA5 hourly data are available with a horizontal resolution of $0.5^{\circ}$ and 37 vertical pressure levels from 1000 to $1 \mathrm{hPa}$; the CCMP wind is available at 6-h with $0.25^{\circ}$ resolution at $10 \mathrm{~m}$ above sea 
level. Furthermore, we used the Weather Research and Forecasting (WRF) Model, version 3.5 (Skamarock et al. 2008; Carvalho et al. 2014), to investigate the atmospheric responses to the Kuroshio SST front over the ECS. Specific experimental solutions are described in Sect. 4.

Firstly, to get the fundamental features of the highfrequency variability activities over the Kuroshio SST front, we calculated the standard deviation (STD) of the wind speed and the wind direction on the different timescale (Fig. 1). The results showed the wind speed diurnal variabilities are significant $(>2.50)$ over ECS, Yellow Sea (YS) and the South China Sea (SCS), especially over the offshore area (Fig. 1a). For the wind speed variabilities within 7-day, the STD distributions are almost consistent with the wind speed diurnal STD but the 7-day STD are greater from 0.1 to 0.25 than 1-day STD approximately. For the wind direction variabilities, the diurnal STDs are remarkably high over the middle-lower Yangtze River region, middle-lower Yellow River, Kuroshio SST front and its warm tongue. The wind direction STDs with 7-day also are almost consistent with the diurnal STD distributions but the 7-day STD are greater from 5 to 10 than 1-day STD approximately. Therefore, whether wind speed STD or wind direction STD over the Kuroshio SST front, there are barely few differences from 1 day to 7 days (the results within the 2, 3, 4, 5, 6 days are not shown here). It suggests that the diurnal variability may play the most important role in the high-frequency variability activities. To confirm this hypothesis, the filtering method is applied to the 6-hourly dataset to extract different fluctuations, including diurnal signals, 1-2 days signals and 2-7 days signals. The results (Fig. S1) certify that the diurnal signals of the wind speed are the most dominant variability of the high-frequency variability events, so are the wind direction results (not shown here). Therefore, we extract the diurnal variations to represent the main features of the high-frequency variability events hereafter. The day with the most dominant diurnal variability is defined as the peak day of one high-frequency variability activities.
To compare the ability of the different datasets in resolving the atmospheric diurnal variability over the Kuroshio SST front, we calculate the diurnal standard deviation (STD) of the near-surface wind speed and wind direction in CCMP, CFSR and ERA5 datasets during winters of 1987-2016. The results (Fig. 3) showed that the wind speed diurnal variabilities are significant over the ECS, Yellow Sea (YS) and South China Sea (SCS), especially over the offshore area. The wind direction diurnal STDs are remarkably high over the middle-lower Yangtze River region, middle-lower Yellow River, Kuroshio SST front and its warm tongue. Therefore, the near-surface wind diurnal variabilities cannot be neglected over Kuroshio SST front. The CCMP results and the CFSR results are almost consistent both in wind speed and wind direction STD distributions. However, the ERA5 shows some different results from the CCMP and CFSR, where the wind speed STD is lower but the wind direction STD is higher. Furthermore, the ERA5 data show the visible wind speed and wind direction bias with CFSR and CCMP on same time (02:00LT, 08:00LT, 14:00LT, 20:00LT) over Kuroshio SST front (Fig. S2).

To represent the intensity of the high-frequency atmospheric variability, we define the high-frequency variability index based on the high-frequency variations of surface $(10 \mathrm{~m})$ wind speed and wind direction. Specifically, the intensity is calculated as the half sum of normalized variance of wind speed and normalized variance of wind direction, every day. Then we divide all the wintertime data to 10 levels (from level -5 to level 5) of different high-frequency variability intensity according to the high-frequency variability intensity (Table 1 ). The level -5 events represent the days with weak high-frequency variability where highfrequency variability intensities are less than one standard deviation of the average index; the level 5 events represent the days with strong high-frequency variability where highfrequency variability intensities are more than one standard deviation of the average index. The other days are divided from level -4 to level 4 with 0.25 standard deviation in every level. For instance, level 1 events are days where
Fig. 3 The statistical results (percent) of HV-WCP events from level -5 events to level 5 events in CFSR (the red bars), ERA5 (the blue bars) and CCMP (the green bars) datasets. The $\mathrm{X}$-axis indicates the different level HV-WCP events (from level -5 events to level 5 events)

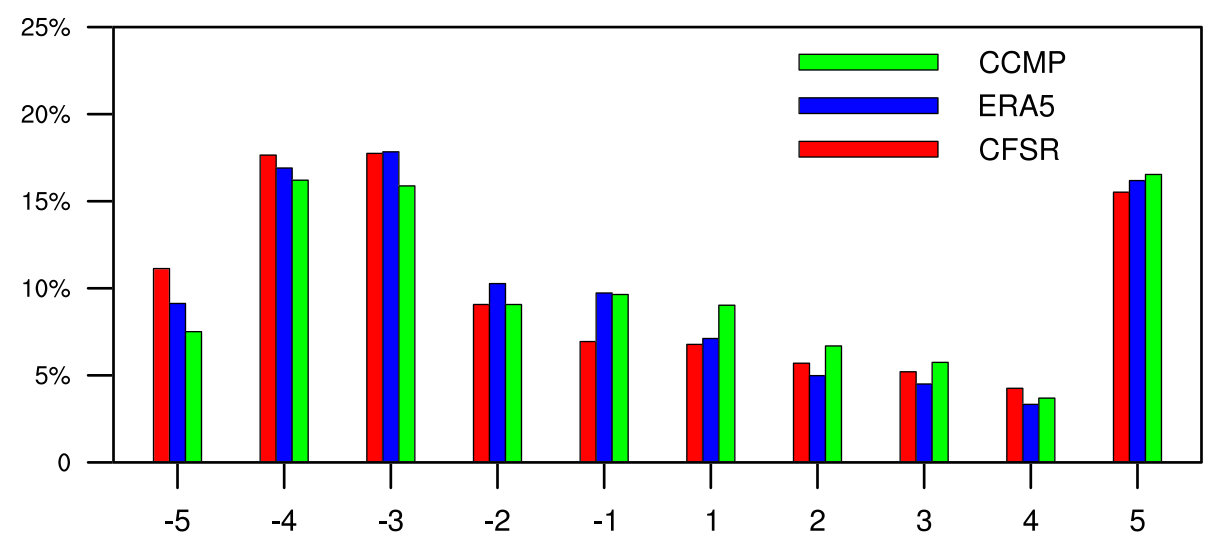


Table 1 Statistical results of the different intensities of HV-WCP events over Kuroshio SST front in CFSR, CCMP and ERA5 datasets

\begin{tabular}{|c|c|c|c|c|c|}
\hline & Level -5 & Level - 4 & Level -3 & Level -2 & Level -1 \\
\hline CFSR (3330 days) & 370 days ( $11.11 \%)$ & 588 days $(17.66 \%)$ & 591 days $(17.75 \%)$ & 302 days $(9.07 \%)$ & 231 days $(6.94 \%)$ \\
\hline ERA5 (3330 days) & 304 days $(9.13 \%)$ & 563 days $(16.91 \%)$ & 594 days $(17.84 \%)$ & 342 days $(10.27 \%)$ & 324 days $(9.73 \%)$ \\
\hline \multirow[t]{2}{*}{ CCMP (2610 days) } & 195 days $(7.47 \%)$ & 413 days $(16.21 \%)$ & 414 days $(15.86 \%)$ & 237 days $(9.08 \%)$ & 252 days $(9.65 \%)$ \\
\hline & Level 1 & Level 2 & Level 3 & Level 4 & Level 5 \\
\hline CFSR (3330 days) & 226 days $(6.79 \%)$ & 190 days $(5.71 \%)$ & 173 days $(5.20 \%)$ & 142 days $(4.26 \%)$ & 517 days $(15.53 \%)$ \\
\hline ERA5 (3330 days) & 237 days $(7.12 \%)$ & 166 days (4.98\%) & 150 days (4.50\%) & 111 days (3.33\%) & 539 days $(16.18 \%)$ \\
\hline CCMP (2610 days) & 236 days $(9.04 \%)$ & 174 days $(6.70 \%)$ & 150 days $(5.75 \%)$ & 96 days $(3.68 \%)$ & 432 days $(16.55 \%)$ \\
\hline
\end{tabular}

high-frequency variability intensities are more than average intensity but less than 0.25 standard deviation of the average index. Table 1 shows the statistical results of the different level events. The high-frequency surface wind variability events will be proven to couple with the high-frequency variability of large-scale stratus precipitation in Sects. 3 and 4. Thus, we define these events as the High-frequency Variability events of the near-surface Wind Coupled with Precipitation (HV-WCP) events. The "High-frequency Variability events" indicates the events with significant variability within time-scale from 1-day to 7-day specifically hereafter.

To show the straightforward view for the distributions of the different level HV-WCP events, we furthered plotted the histogram (Fig. 4) of statistical results (the days and percent of every level HV-WCP events) of HV-WCP events from level -5 events to level 5 events in CFSR, ERA5 and CCMP datasets. The results suggest that the percentage of every level (from -5 to +5 ) $\mathrm{HV}-\mathrm{WCP}$ events in CCMP data are most consist with the percentage in CFSR data and ERA5 data. The composite results for the 10 levels of HVWCP events are also almost consistent for CCMP, CFSR and ERA5 datasets. Furthermore, the HV-WCP events with strongest intensity (level 5) account for significant percentages in the three different datasets: $16.55 \%, 15.53 \%$ and $16.18 \%$ in CCMP, CFSR and ERA5 datasets, respectively. The level 5 percentage are obviously much greater than level 4 percentage $(4.26 \%$ in CFSR; $3.33 \%$ in ERA5; $3.68 \%$ in CCMP). This percentage mutation between level 4 and level 5 suggested the particularity and importance of the level 5 events. Besides, the specific strong HV-WCP days (level 5 events) are generally consistent in three datasets (Fig. S3). Thus, it follows that over the Kuroshio SST frontal region, such strong HV-WCP events are important events during wintertime, and cannot be neglected in climatological statistics. However, previous studies about the high-frequency cycle did not pay enough attention to the high-frequency variability of surface wind in this region.

The CCMP V2 wind analysis product is produced using satellite, moored buoy, and model wind data, and as such, are considered to be a level-3 ocean vector wind analysis product. Compared to the CCMP data, the CFSR data and ERA5 data support more layers and other related variables such as SLP, geopotential height, specific humidity, precipitation among others. Moreover, the hourly ERA5 data can provide more detailed revolution of atmospheric highfrequency process. However, the high-frequency STD distributions of the wind speed and wind direction over Kuroshio SST front in ERA5 data are distinct from CCMP and CFSR datasets. In order to analyze the specific characteristics, climate effects and possible mechanisms of the strong HV-WCP events over the Kuroshio SST front accurately, we therefore mainly use the CFSR data hereafter, and use the ERA5 hourly data to give more detailed revolutions. The differences between ERA5 data and CFSR data will be discussed in Sect. 5.

What are the specific characteristics related to significant high-frequency variability events of the near surface wind over the Kuroshio SST front? Figure 5 shows the composite results of the surface wind field anomalies and vorticity anomalies for level 5 events in the CFSR data. The Student's $t$ test is used to determine the statistical significance of the composites. It is revealed that the southerly wind anomalies appear to accompany the cyclonic circulation anomalies at 02:00 local time (LT) over the core front and cold side of the SST front. At 08:00 LT, the cyclonic anomalies gradually move southeast as the southerly wind anomalies weaken. At 14:00 LT, the surface wind field becomes northwest wind anomalies, and the maximum vorticity anomaly center continues moving southeastward. This process continues until 20:00 LT, when the local circulation turns into strong northwestern wind anomalies, as the maximum vorticity anomaly center moves to the warm pool of the Kuroshio SST front. Generally, from 02:00 LT to 20:00 LT, the 10-m wind field gradually changes from a southerly wind anomaly to a northwest wind anomaly. The accompanying maximum vorticity anomaly center moves from the cold side of the Kuroshio SST front to southeast, and finally reaches the warm flank of the Kuroshio.

To further diagnose the characteristics and climatic effects of these high-frequency variability events, we adopt 


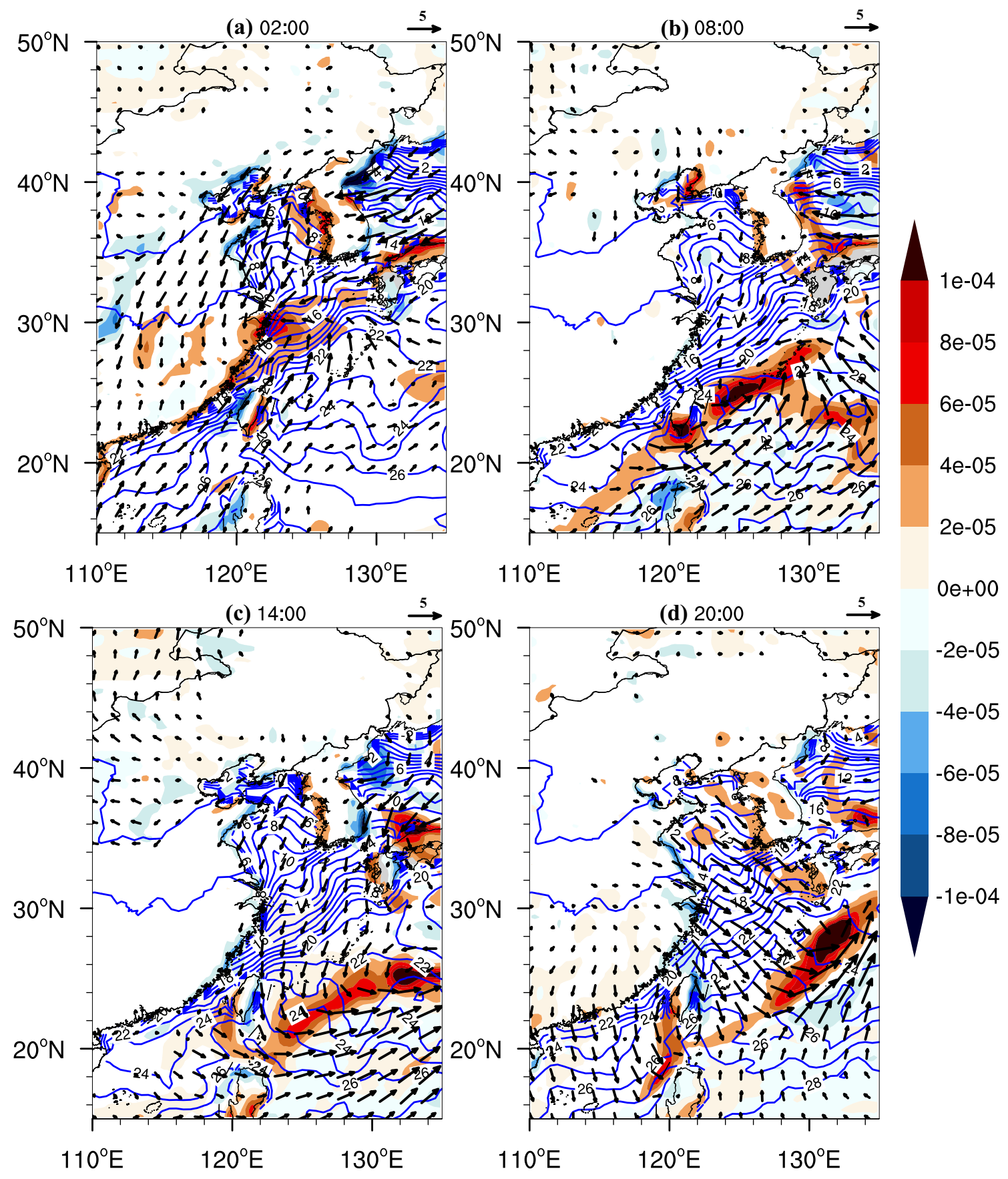

Fig. 4 High-frequency variations of the wind field (m/s), vorticity (shadings; $10^{-5} / \mathrm{s}$ ) and SST (contours; ${ }^{\circ} \mathrm{C}$ ) of level $5 \mathrm{HV}-\mathrm{WCP}$ events at a 02:00, b 08:00, c 14:00, and d 20:00 LT in CFSR data. All shaded values exceed 95\% confidence level

a rotated empirical orthogonal function (EOF) analysis method in this study. For the traditional EOF method, the spatial fields separated by EOF have poor ability to indicate the characteristics of different geographical regions, with large sampling errors. To avoid these shortcomings of the traditional EOF, the rotated EOFs are obtained using the Varimax rotation method (Richman and Lamb 1985; Richman 1986). The several leading EOFs entering the rotation are determined based on the criterion by O'Lenic and Livezey (1988). The rotation relaxes the orthogonality and the rotated patterns are more analogous to the teleconnected patterns (Barnston and Livezey 1987). Therefore, the structure of the typical spatial field is clearer after rotation, which not only reflects the varying characteristics of different regions, but also reflects the spatial correlation distributions of different regions. Due to the complex underlying 

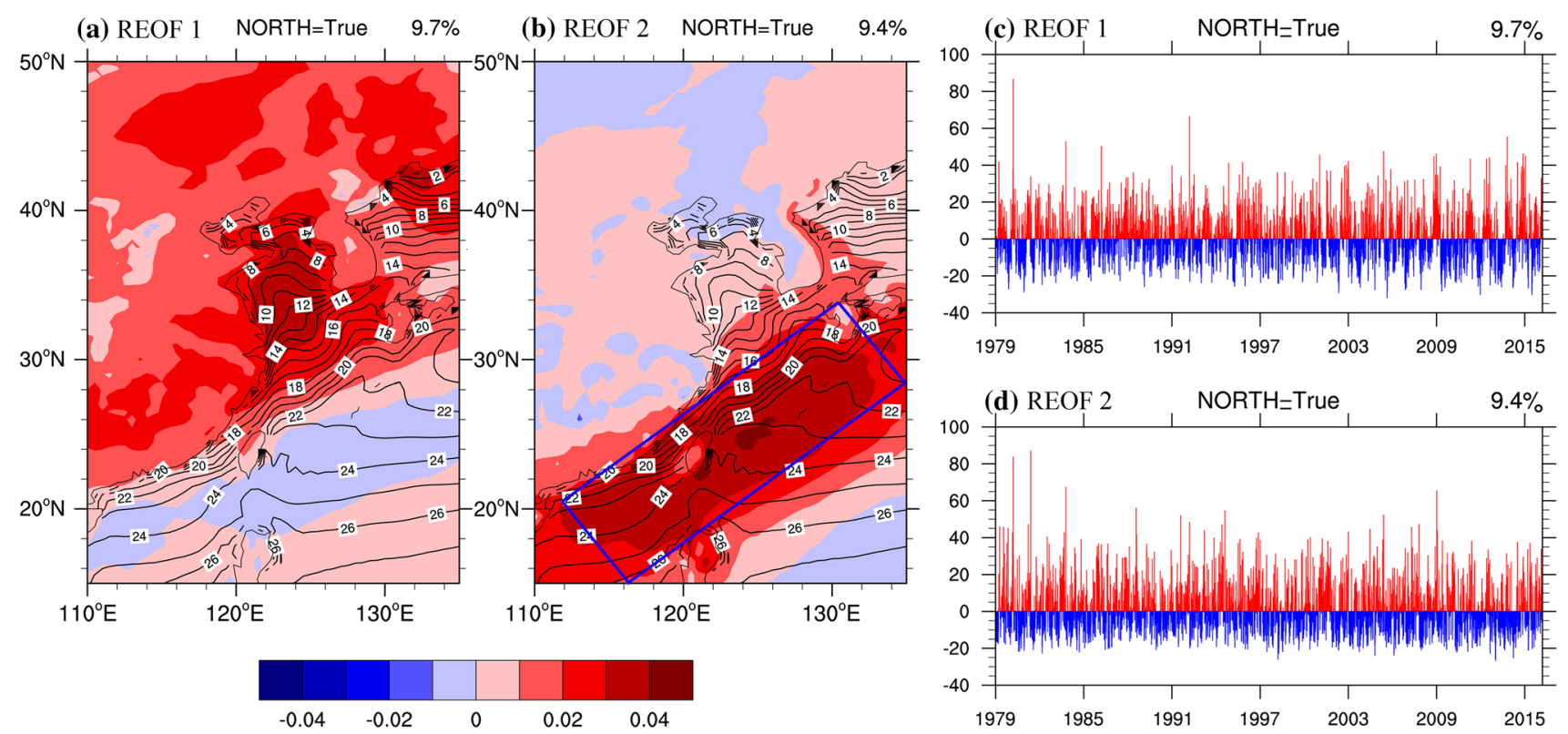

Fig. 5 The $\mathbf{a}$ first and $\mathbf{b}$ second modes of rotated EOF analysis (shadings) on wind high-frequency variabilities and the SST (contours; ${ }^{\circ} \mathrm{C}$ ) over the region $15^{\circ} \mathrm{N}-50^{\circ} \mathrm{N}, 110^{\circ} \mathrm{E}-135^{\circ} \mathrm{E}$ during the winters of

conditions and the topographical structure, the rotated EOF method is adopted over the Kuroshio region and associated coastal regions.

The rotated EOF analysis method is performed to analyze the near surface wind high-frequency variabilities over the region $15^{\circ} \mathrm{N}-50^{\circ} \mathrm{N}, 110^{\circ} \mathrm{E}-135^{\circ} \mathrm{E}$ during the winters (December, January, and February) of 1979-2016 (3330 days in total). We calculated the simultaneous regressions of related variables on the normalized first and second principal components of the rotated EOFs ( $\mathrm{PC} 1$ and $\mathrm{PC} 2$ ). Figure 2 shows the first two leading rotated EOF modes and time series of PC1 and PC2. The rotated EOF1 and EOF2 can explain $9.7 \%, 9.4 \%$ of the wind high-frequency variabilities respectively, which indicates that the first two EOFs almost contribute equally to the total variance. In rotated EOF1, the areas with strong high-frequency variabilities include coastal areas of China, Bohai Bay areas and other areas with complex underlying conditions. Previous studies have explained the high-frequency variabilities of surface wind fields well over these areas (Hamilton 1980; Krishnamurti et al. 2000; Ciesielski and Johnson 2008; Chen et al. 2009, 2013; Du et al. 2012; Du and Rotunno 2014, 2018). However, for rotated EOF2, the strongest high-frequency variabilities occur over the core and warm pool of the Kuroshio SST front in the ECS, which is consistent with the key area where the high-frequency variabilities of surface wind are obvious, in the composite results of level 5 events. Furthermore, the ERA5 rotated EOF results are consistent with the CFSR data (Fig. S4). Therefore, the rotated EOF results again testify to
1979-2016 in CFSR data. The blue box in b represents the key Kuroshio SST front in the study. c, d Shows the corresponding PC1, PC2 time series of the first and second modes

the significance of these strong high-frequency variability events. For the strong high-frequency variability events as shown by EOF2, what are the specific characteristics of the related HV-WCP events? How about its formulation mechanism? What are the specific climate effects? Hereafter, this study will focus on these key issues.

\section{The characteristics of HV-WCP events over Kuroshio SST front}

\subsection{The large-scale conditions of HV-WCP events}

The high-frequency variations of the surface wind field obtained in Sect. 2 mainly occur over the Kuroshio SST frontal areas in the ECS. What are the large-scale circulation conditions that correspond to these local-scale events? To get the corresponding large-scale background state corresponding to the strong HV-WCP events, we firstly make a 5-day moving average for different intensity HV-WCP events. Then we calculate the differences of geopotential height and wind fields between the level 5 events with the strongest highfrequency variation intensity and the level -5 events, with the weakest intensities at $850 \mathrm{hPa}$ and $500 \mathrm{hPa}$, respectively (Fig. 6a, b). The 500hpa height field difference results show that when strong HV-WCP events occur, significant positive geopotential height anomalies appear over the Japan, YS and ECS, while significant negative geopotential height anomalies occur over the Siberia region. Moreover, there are significant 
Fig. 6 The composited 5-days average $850 \mathrm{hPa}$ (a) and $500 \mathrm{hPa}(\mathbf{b})$ geopotential heights (shadings; gpm) and wind fields anomalies (arrows; $\mathrm{m} / \mathrm{s}$ ) differences between level 5 HV-WCP events and level -5 HV-WCP events during the winters of 1979-2016 in CFSR data. All the shaded areas exceed $95 \%$ significance level. $\mathbf{c}$ Is the composited wind speed (red), wind shear (blue) and buoyancy (green) over the Siberian region within the PBL under different intensity level events. The $\mathrm{X}$-axis indicates the intensity level. All shaded values exceed the $95 \%$ confidence level
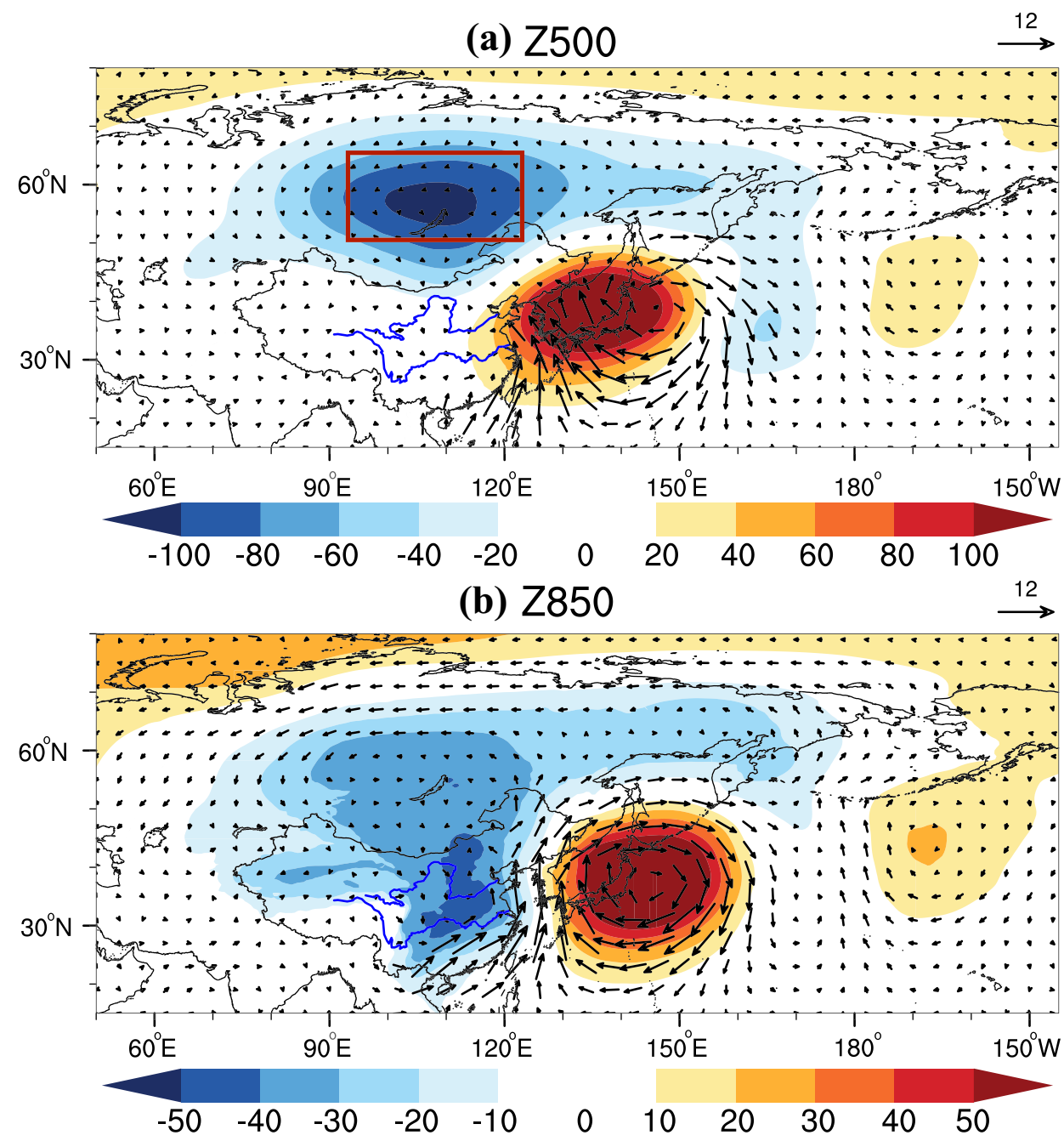

(c) wind speed\&wind shear

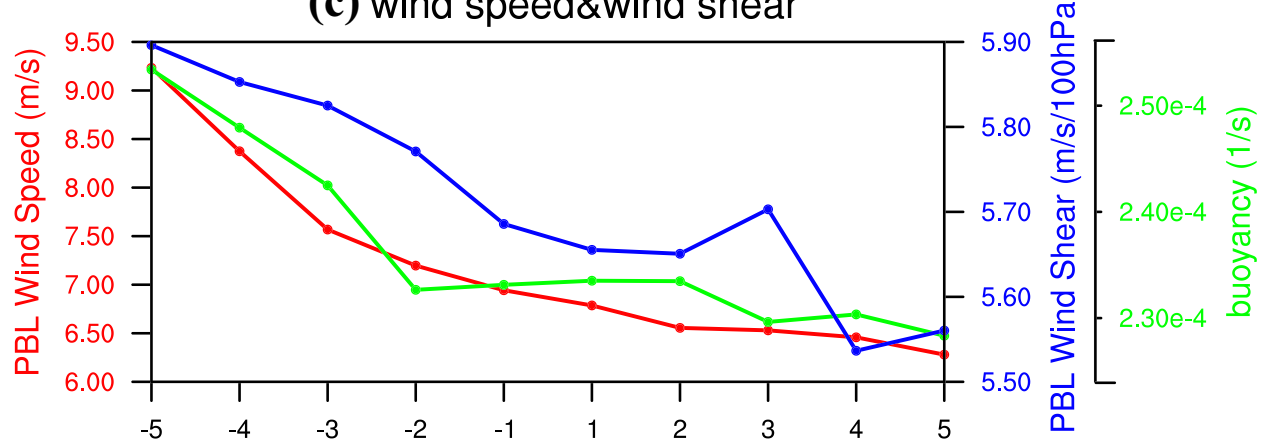

southeast wind anomalies over the ECS that accompany the anomalies in the geopotential height field. The equivalentbarotropic structure circulation anomalies are remarkable over the mid-latitude region. The distributions of height field and wind field anomalies at $850 \mathrm{hPa}$ are similar to those at $500 \mathrm{hPa}$, although the negative geopotential height anomalies develop further to the south. The pronounced negative height anomalies extend from the Siberia region to the middle and lower reaches of the Yangtze River.
During wintertime, due to the control of the East Asian winter monsoon system, the prevailing northwesterly wind is dominant over the ECS. Therefore, when strong HV-WCP events occur, the prevailing northwest winter wind and the accompanying cold air activity tend to weaken because of the attenuated Siberian high and the Mongolian highpressure center. Meanwhile, vertical mixing within the PBL tends to decrease because of the weakened monsoon. Figure $6 \mathrm{c}$ showed the regional averages of the wind speed and 
the vertical mixing rate, represented by the vertical wind shear in the boundary layer, and the buoyancy term within the PBL over the Siberian region (red box in Fig. 6a). The squared buoyancy frequency is calculated as:

$N^{2}=-\left(\frac{g}{\rho} \frac{d \rho}{d z}\right)$

in which $g$ is the acceleration due to gravity and $\rho(z)$ is density as a function of height $\mathrm{z}$. It is also called Brunt-Vaisala frequency. This frequency is also sometimes used as a measure of the stability within a statically stable environment. The result indicates that with the intensity of HVWCP events increasing, the average wind speed and vertical mixing in the upstream region of the ECS tends to decrease gradually. Although the vertical mixing intensity of level 4 events is stronger than that of level 5 events, the overall trend is still weakening. The tendency of the buoyancy term is generally consistent with the result of the vertical wind shear within PBL. Thus, the large-scale circulation conditions with weaker monsoon and the weaker vertical mixing tend to create conditions for the occurrence of the near-surface highfrequency wind variability events over the Kuroshio SST front area during wintertime.

\subsection{The features of HV-WCP events}

What about the specific features of the atmospheric highfrequency variation events? In Sect. 2, we show the composite results of the HV-WCP level 5 events indicating that from early morning to evening hours, specifically 02:00 LT to 20:00 LT, the surface wind turned from the southerly anomaly to the northwest anomaly and the maximum vorticity anomaly center moved from the cold side of the Kuroshio SST front to warm flank. We averaged the wind speed of the level 5 HV-WCP events over the Kuroshio and further decomposed the wind field into geostrophic and ageostrophic components. The geostrophic wind components are computed from the geopotential height fields and the ageostrophic components are calculated by subtracting the geostrophic components from the total wind, where the Coriolis parameter takes its local value. For both CFSR and CCMP datasets, the results (Fig. 7a) suggest that when strong HVWCP events occur, the surface wind speed over the Kuroshio SST front increases gradually from 02:00 LT to 20:00 LT (approximately $1.5 \mathrm{~m} / \mathrm{s}$ ). More importantly, the main contributions to the high-frequency variation of the wind speed is from the high-frequency change of geostrophic components. The variabilities in the high-frequency ageostrophic components caused by the inertial oscillation of the boundary layer are relatively weak (less than $0.40 \mathrm{~m} / \mathrm{s}$ ). The ERA5 hourly data showed the consistent results of the high-frequency surface wind speed, the ageostrophic components and geostrophic components. Therefore, it is suggested that the high-frequency variabilities of level 5 HV-WCP events are not dominated by the inertial oscillation mechanism of the boundary layer over the Kuroshio SST front. Moreover, the intensity of the high-frequency wind variations is reduced gradually with increasing geopotential height (Fig. 7b). The high-frequency variabilities almost disappeared at the middle and high troposphere. Thus, we suggest that HV-WCP events have special features which distinguish them from sea-land breeze phenomena with obvious baroclinic structure. Furthermore, we calculated the high-frequency variations for average precipitation in level 5 HV-WCP events over the Kuroshio SST front in CFSR and ERA5 datasets. Associated with the variabilities in local high-frequency circulation, the precipitation also has significant high-frequency variations over the Kuroshio SST front. However, different from previous studies (Chen et al. 2009, 2013; Du et al. 2012; Du and Rotunno 2014, 2018) we find that the trend for variability of the high-frequency precipitation is inconsistent with the trend for wind speed over the Kuroshio SST front. In CFSR results, the precipitation gradually decreased from 02:00 LT to 20:00 LT and reached a minimum value at 20:00 LT, at night. The ERA5 hourly data showed the more detailed precipitation revolution, where the precipitation increased from 01:00 LT to 06:00 LT, then reduced gradually from morning (06:00 LT) to moon night. Variation in precipitation may be related the abnormal turning of the wind direction from previous composited results (Fig. 5). We will provide additional discussion of the specific relationship between the high-frequency variabilities of precipitation and the wind field for HV-WCP events in a later section of this paper.

However, the composited results of the level 5 HV-WCP events are not capable of describing the specific characteristics for the different intensity atmospheric high-frequency variation events. It is complicated to analyze the specific local circulation and associated climate effects for 10 intensity events considered here. Therefore, to reveal the climatic characteristics of the atmospheric high-frequency variation over the Kuroshio SST front, a regression analysis is applied to the CFSR wintertime data and the Student's t test is used to determine the statistical significance of the regression results. Figure 8 presents a regression of the $10 \mathrm{~m}$ wind field and the average vertical speed within the PBL on PC2. The pronounced cyclonic wind anomaly and vertical speed anomaly can be seen over the ECS, which shows the highfrequency variation with a southeastward propagation. At 02:00 LT, the cyclonic anomaly center is over the coastal area of the YS. The significant southerly wind anomaly and the upward vertical speed appear over the Kuroshio SST front. At 08:00 LT, the center of the cyclonic anomalies and the maximum upward vertical speed anomaly gradually move southeastward accompanied with the southerly 
Fig. 7 a Shows the composited high-frequency variations of the level 5 HV-WCP events over Kuroshio SST front during the winters of 1979-2016 in CFSR data and ERA5 data. The black line is the composited 10-m wind speed $(\mathrm{m} / \mathrm{s})$, the red line is the geostrophic wind speed $(\mathrm{m} / \mathrm{s})$, the blue line is the ageostrophic wind speed $(\mathrm{m} / \mathrm{s})$ and the green line is the Kuroshio SST front average precipitation $\left(\mathrm{kg} / \mathrm{m}^{2}\right)$. The circle solid lines are CFSR data results and the triangle dotted lines are ERA5 data results. The $\mathrm{X}$-axis represents the local time from 02:00 LT to 20 LT. b Shows the composited high-frequency variations of the level 5 events wind speed $(\mathrm{m} / \mathrm{s})$ on different altitude levels. The red line, blue line, brown line, green line, purple line and black line are the wind speed $(\mathrm{m} / \mathrm{s})$ at $975 \mathrm{hPa}, 950 \mathrm{hPa}, 925 \mathrm{hPa}$, $900 \mathrm{hPa}, 850 \mathrm{hPa}$ and $750 \mathrm{hPa}$ respectively. The solid circle, hollow circle, triangle and star represents the wind speed $(\mathrm{m} / \mathrm{s})$ at 02:00 LT, 08:00 LT, 14:00 LT and 20:00 LT respectively. The $\mathrm{X}$-axis represents $\mathrm{U}$ wind and $\mathrm{Y}$-axis represents $\mathrm{V}$ wind
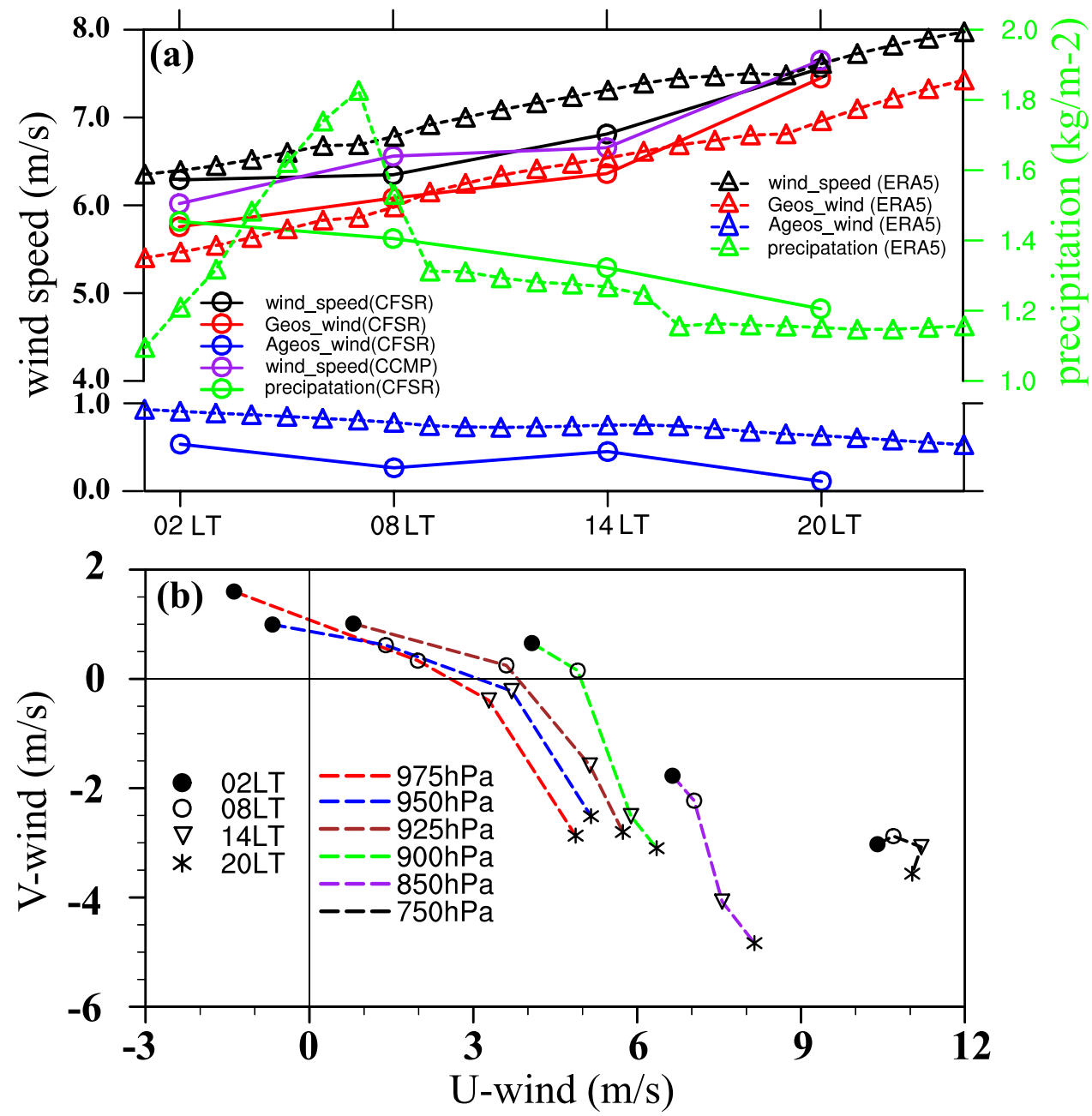

wind anomaly and weakening of the upward vertical speed anomaly. Thereafter, and specifically at 14:00 LT, the vorticity anomaly center and the significant upward vertical speed anomaly continue moving southeastward. This process continues until 20:00 LT, when the local circulation transforms into strong northwestern wind anomalies over the Kuroshio SST front. Concomitantly, the center for the significant upward vertical speed and vorticity anomaly moves to the warm pool of the Kuroshio SST front. From 02:00 LT to 20:00 LT, the cyclonic anomaly center and associated upward vertical speed anomaly move from the cold side of the Kuroshio SST front to the southeast, and finally reach the warm flank of the Kuroshio. The accompanying 10-m wind direction gradually turns, changing from a southerly wind anomaly to a northwest wind anomaly, and the total wind speed gradually increases over the Kuroshio SST front.

\subsection{Climate effects related to HV-WCP events}

Numerous previous studies have demonstrated that highfrequency variability of local-scale circulations have remarkable impact on the local climate, especially for local precipitation and its high-frequency variabilities (Ramage 1952; Wai et al. 1996; Fujinami and Yasunar 2001; Terao et al. 2006; Chen et al. 2009, 2013; Du et al. 2012; Du and Rotunno 2014, 2018). Moreover, the SST front can anchor rain bands by triggering deep cumulus convection along the warm current in winter, resulting in precipitation anomalies over adjacent regions (Tokinaga et al. 2005, 2006; Minobe et al. 2008; Kuwano-Yoshida et al. 2010; Xu et al. 2011; Sasaki et al. 2012; Xu and Xu 2015). A composite analysis of level $5 \mathrm{HV}$-WCP events (Fig. 7) also shows that precipitation over the Kuroshio has a significant decreasing trend from morning to night in strong HV-WCP events. What about the specific patterns of the precipitation anomaly when strong HV-WCP events happen?

We calculated the regression of precipitation anomaly on PC2 from 02:00 LT to 20:00 LT in CFSR data. The regression results (Fig. 9a-d) show that there is a robust precipitation anomaly over the middle and lower reaches of the Yangtze River, the southeast coast of China, the ECS and the Japan. Furthermore, from 02:00 LT to 20:00 LT, the 
Fig. 8 The high-frequency variations of the regression wind field (arrows; $\mathrm{m} / \mathrm{s}$ ) and vertical wind speed (shadings; $\mathrm{m} / \mathrm{s}$ ) against PC2 over Kuroshio SST front during the winters of 1979-2016 in CFSR at a 02:00 LT, b 08:00 LT, c 14:00 LT, and d 20:00 LT respectively. All shaded values exceed $95 \%$ confidence level
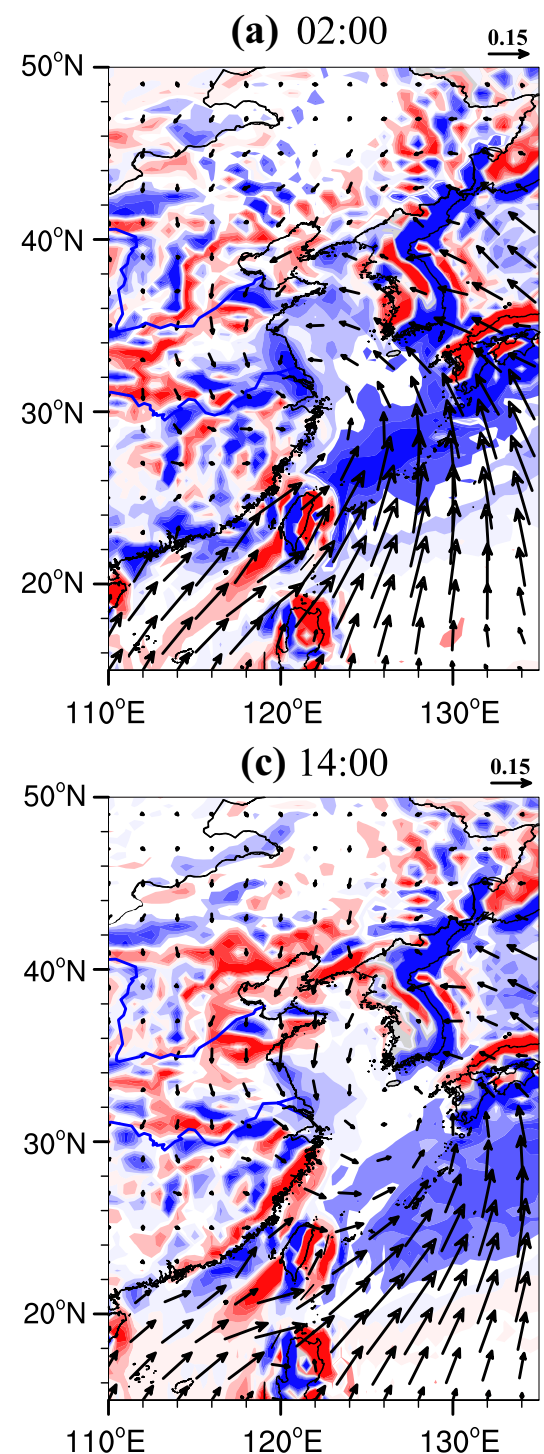

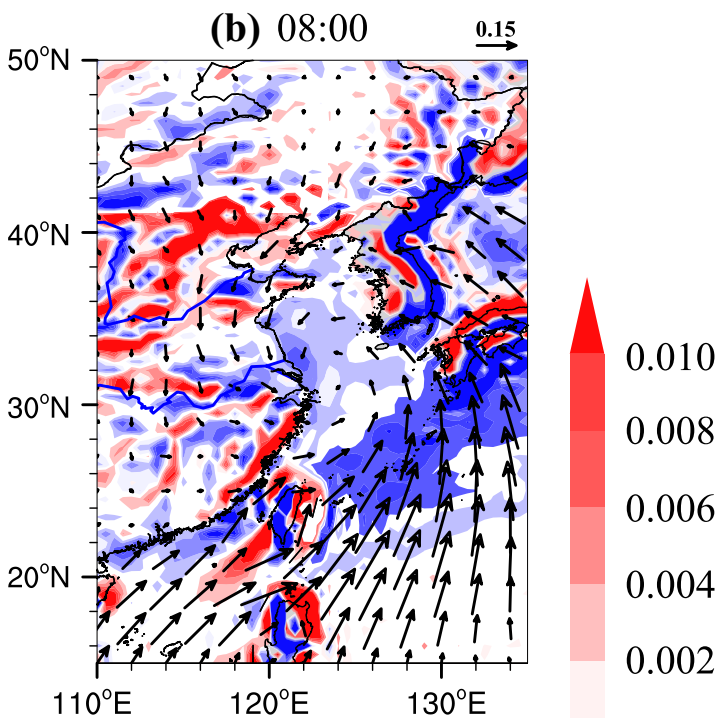

0.000

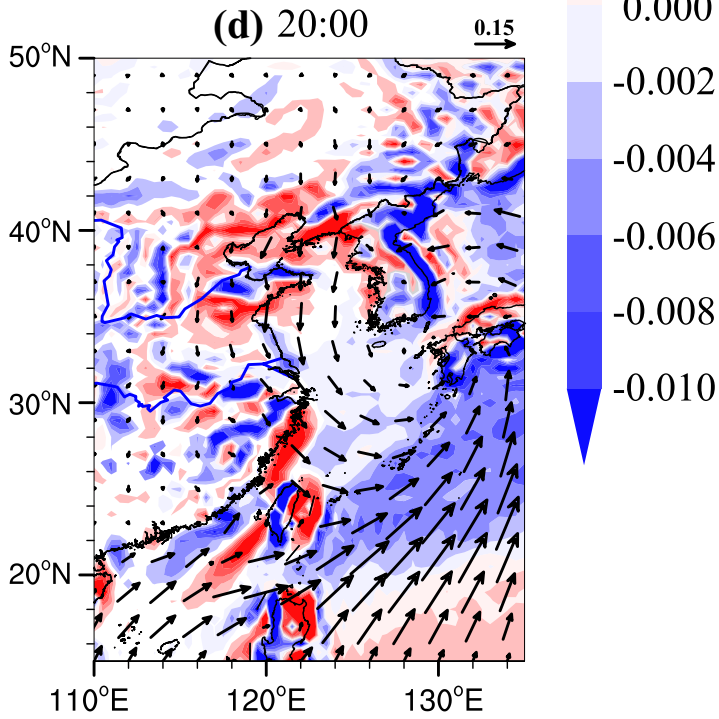

precipitation anomaly is gradually reduced and the rainband moves southeastward. The center of the precipitation anomaly moves from the China coast to the warm flank of the Kuroshio SST front, which is consistent with the highfrequency variation of the cyclonic anomaly and related updrafts. We further divide the total precipitation into largescale stratus precipitation and local-scale convective precipitation (Fig. 9e-1). It is notable that the stratus precipitation and convective precipitation have significant high-frequency variation over the Kuroshio SST front. Moreover, the highfrequency variability characteristics of the stratus precipitation regression and convective precipitation regression are analogous to the total precipitation regression results. However, in terms of precipitation intensity and range, there are significant differences between stratus precipitation and convective precipitation anomalies. Like the total precipitation anomaly patterns, the large-scale stratus precipitation anomalies are remarkable over the middle and lower reaches of the Yangtze River, the southeast coast of China, the ECS and the Japan. By comparison, the small-scale convective precipitation anomalies are mainly located over the core SST front and the warm pools of the Kuroshio SST front. However, most of the contribution to the precipitation anomaly is from stratus precipitation anomaly (more than $70 \%$ of the total precipitation), over Kuroshio SST front and its warm flank areas. Furthermore, the ERA5 regression precipitation results are consistent with CFSR results (Fig. S6-Fig. S8). Therefore, it is suggested that the strong HV-WCP events have considerable climate effect not only on the localscale precipitation but also on the large-scale precipitation anomaly. More importantly, we notice that the intensity and movement trend of the rainband high-frequency variation have a similar configuration relationship as shown in the cyclonic circulation and the updraft anomaly. How is it that the high-frequency wind variability and the corresponding high-frequency precipitation variability can be formed over 


\section{Total precipitation}
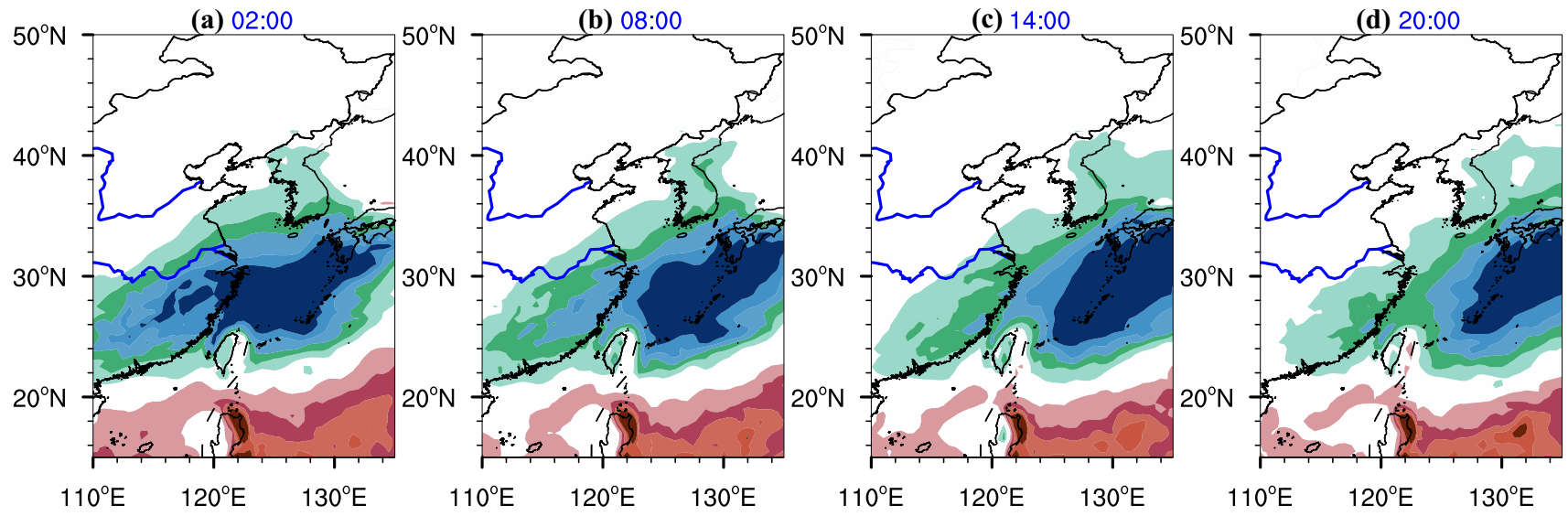

Status precipitation
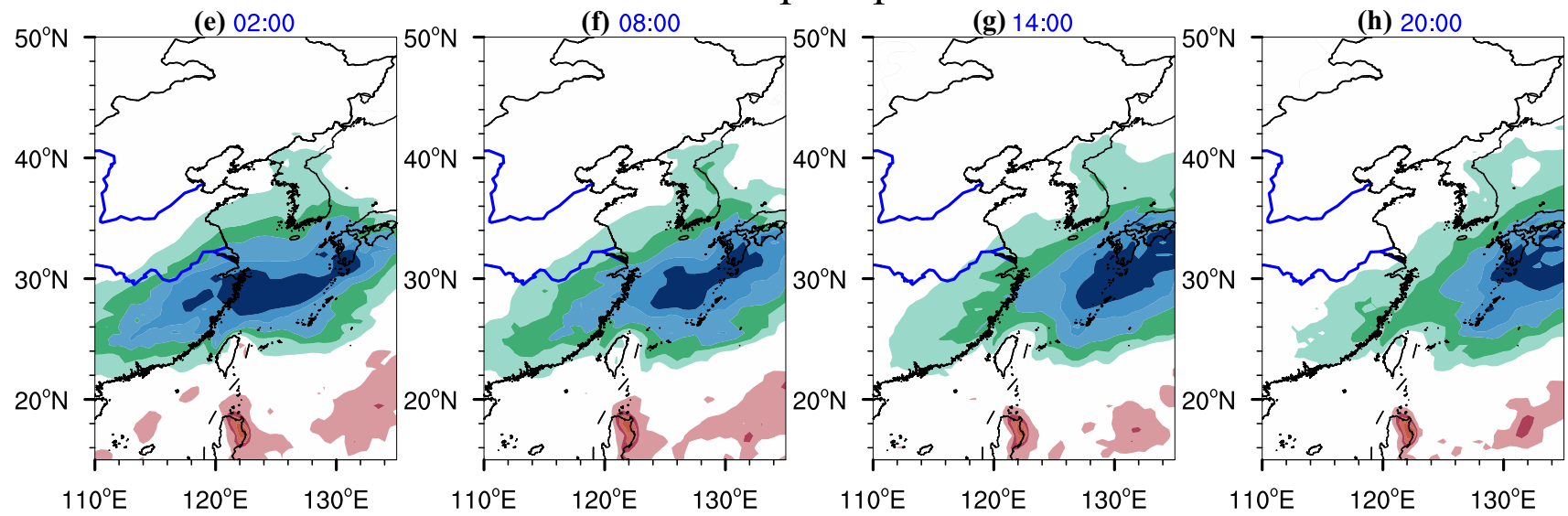

Convective precipitation
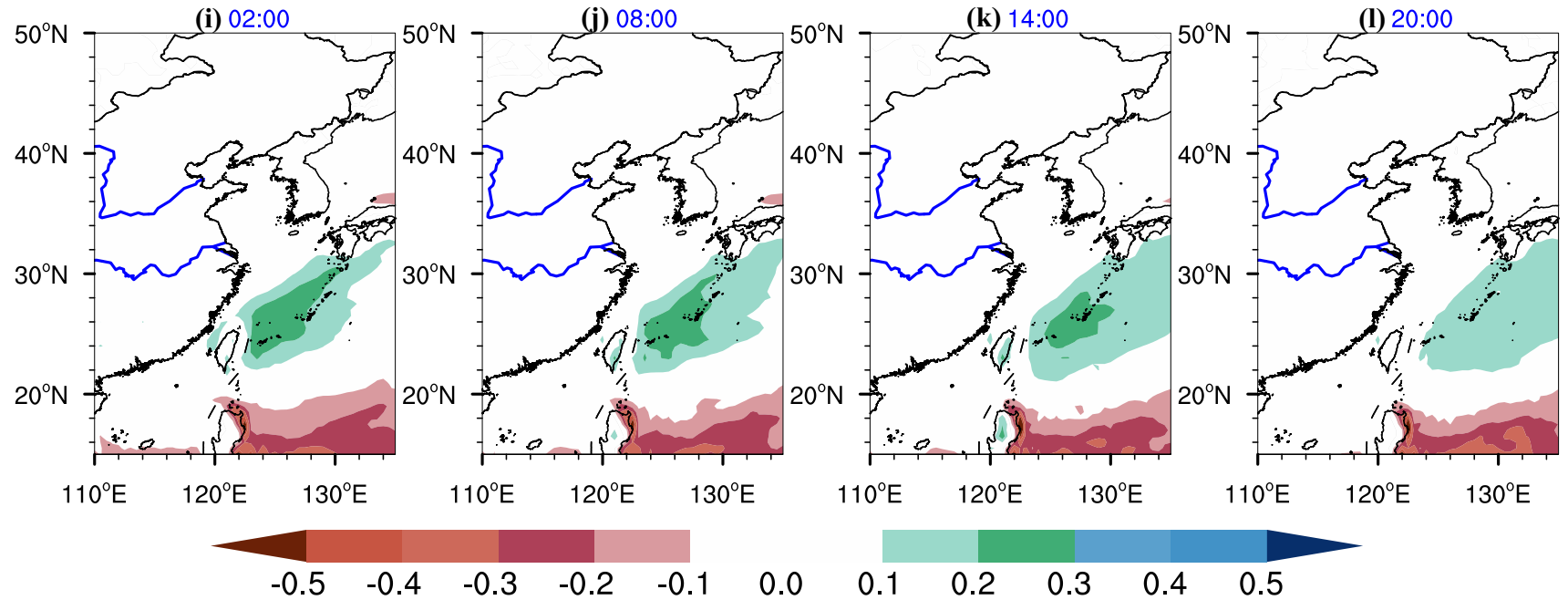

Fig. 9 The high-frequency variations of the regression precipitation $\left(\mathrm{kg} / \mathrm{m}^{-2}\right)$ against PC2 over Kuroshio SST front during the winters of 1979-2016 in CFSR data at 02:00 LT (a, e, i), 08:00 LT (b, $\mathbf{f}, \mathbf{j})$, 14:00 LT $(\mathbf{c}, \mathbf{g}, \mathbf{k})$, and 20:00 LT $(\mathbf{d}, \mathbf{h}, \mathbf{l})$ respectively. a-d Are the total precipitations regressions, $\mathbf{e}-\mathbf{h}$ are large-scale precipitations regressions and $\mathbf{i}-\mathbf{l}$ are the convective precipitations regressions. All shaded values exceed $95 \%$ confidence level 
the Kuroshio SST front? What is the rigorous relationship between cyclonic circulation, upward vertical speed and precipitation over the Kuroshio SST front? We will try to solve these questions in the following sections.

\section{The mechanism of the HV-WCP events}

\subsection{The local circulation and precipitation relationship in HV-WCP events}

High-frequency variations of the precipitation anomaly, cyclonic circulation anomaly and the upward flow have been identified, with consistent high-frequency trends in the intensity and motion. We speculate that high-frequency atmospheric variability events may be a process that is coupled with precipitation and local circulation. To elucidate the specific evolution of HV-WCP events, we have calculated the lag-lead regression of the surface wind field, vertical motion within the PBL and precipitation on PC2. In this approach, we firstly select the cross-section perpendicular to the core Kuroshio SST front and calculate the PBL height, moisture flux and its divergence regressions on PC2, using PC2 leading 2 days to lagging 1 day (Fig. 10). It is obvious that the PBL height and the moisture have significant variations, from PC2 leading 2 days to lagging 1 day. With PC2 leading 2 days, although the PBL height is lower over the Kuroshio cold side but higher over the warm side, there is no obvious difference between warm flank and cold flank. The PBL height changes very little (less than $15 \mathrm{hPa}$ ) until PC2 leading 1 day. With PC2 leading 0 day, the PBL distribution over the Kuroshio is found to be no longer uniform, as before. A significant PBL height gradient occurs, resulting from reductions in the PBL height over the warm flank of SST front, but decreases over the cold side, which is mainly caused by the Kuroshio SST front thermal effect on the turbulent heat flux, including the sensible heat flux $(\mathrm{SH})$ and the latent heat flux (LH). This considerable PBL height gradient is subsequently suppressed high-frequency, with PC2 lagging 1 day, making the PBL structure more uniform. Meanwhile, there is no significant high-frequency variation of PBL height, from PC2 leading 2 days to PC2 lagging 1 day. The PBL height remains basically unchanged during the day. With the evolution of the PBL structure, the moisture conditions have significant variation, from PC2 leading 2 days to PC2 lagging 1 day. With PC2 leading 2 days, the moisture flux and its convergence can be negligible over Kuroshio SST front, almost throughout this event. Until 20:00 LT, the visible westward and upward moisture anomalies appear over the warm side. By the next day, the eastward moisture transport is further enhanced and its convergence occurs within the PBL. With PC2 leading 0 day, the enhanced moisture and simultaneous PBL height gradient generates plentiful water vapor, transporting from the PBL to the free atmosphere, bringing about significant moisture convergence over the core SST front. Furthermore, the upward and westward moisture flux, and its convergence, reach the maximal strength at 02:00 LT, which is conducive to the occurrence of the precipitation anomaly peak. After 02:00 LT, the westward and upward moisture transport is gradually reduced, resulting in weakening of the moisture convergence and as it is moved to the warm side of the Kuroshio SST front. Although the upward water vapor is still active until 20:00 LT, the westward moisture and moisture convergence almost disappear over the Kuroshio SST front. When PC2 lagging 1 day, the moisture flux and its convergence weakened with the uniform PBL structure. Ultimately, the moisture conditions are restored to the previous weak conditions when PC2 leading 2 days.

When PC2 leading 0 day, we notice that the PBL height has negligible high-frequency variation but the high-frequency variabilities of moisture flux and its convergence weaken significantly from 02:00 LT to 20:00 LT. Thus, it is suggested that the high-frequency variation of the moisture conditions is not caused by the high-frequency variation of the PBL structure. The significant PBL height gradient supports appropriately suitable conditions to generate the plentiful moisture transport from the PBL into the free atmosphere, but does not support the conditions needed to generate the high-frequency variation of the moisture and its convergence. With the associated features, the local circulations testify that the cyclonic anomaly center and associated upward vertical motion anomaly is moved from the cold side of the Kuroshio SST front to southeast, and finally reaches the warm flank of the Kuroshio during the time from 02:00 LT to 20:00 LT (Fig. 7). The cyclonic anomaly and updrafts can bring about upward moisture and the southeast wind anomaly due to the cyclonic motion which can enhance the eastward moisture transport. Therefore, the high-frequency variations of moisture conditions are significantly associated with the local circulation dynamics. For the local circulations, which process dominates its high-frequency variability?

Based on the Ertel potential vorticity equation (Ertel 1942; Hoskins et al. 1985), the complete form of the vorticity tendency equation is expressed as (Wu and Liu 1998; Wu et al. 1999; Lit et al. 2001):

$$
\begin{aligned}
\frac{\partial \zeta}{\partial t}+\vec{V} \cdot \nabla \zeta+\beta v= & -(f+\zeta) \nabla \cdot \vec{V}+\frac{f+\zeta}{\theta_{z}} \frac{\partial Q}{\partial z} \\
& +\frac{1}{\theta_{z}} \frac{\partial u}{\partial z} \frac{\partial Q}{\partial y}-\frac{1}{\theta_{z}} \frac{\partial v}{\partial z} \frac{\partial Q}{\partial x}
\end{aligned}
$$

where $\zeta$ is relative vorticity, $\overrightarrow{\mathrm{V}}=(u, v)$ represents the horizontal wind, $\nabla$ represents the horizontal gradient operator, $f$ represents the planetary vorticity and $\beta$ represents its 


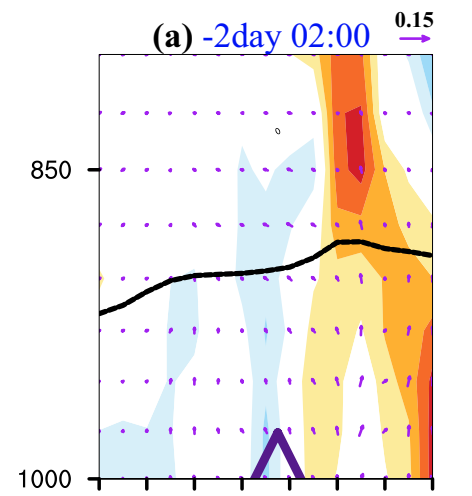

$\begin{array}{llllllll}33 & 32 & 31 & 30 & 29 & 28 & 27 & 26\end{array}$

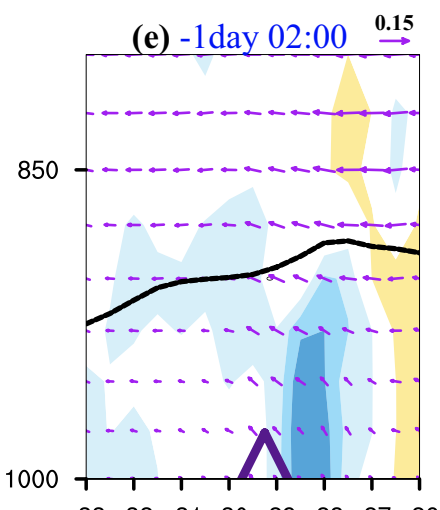

$\begin{array}{llllllll}33 & 32 & 31 & 30 & 29 & 28 & 27 & 26\end{array}$

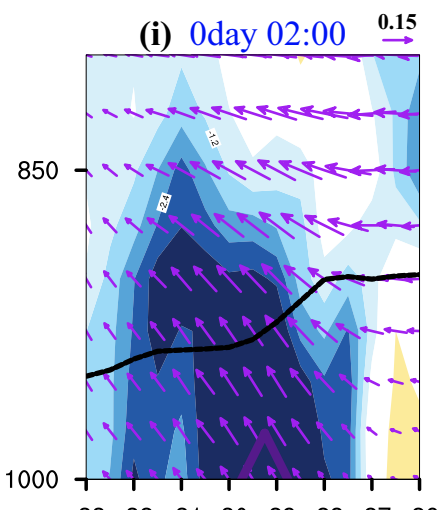

$\begin{array}{llllllll}33 & 32 & 31 & 30 & 29 & 28 & 27 & 26\end{array}$ (b) -2day 08:00 $\stackrel{\mathbf{0 . 1 5}}{\rightarrow}$

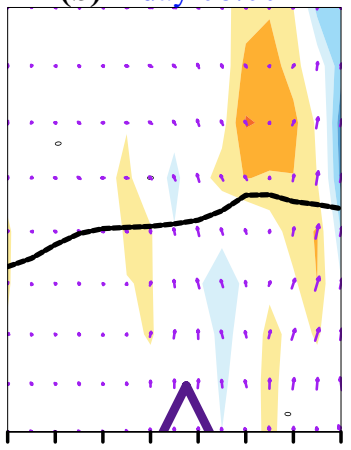

$\begin{array}{llllllll}33 & 32 & 31 & 30 & 29 & 28 & 27 & 26\end{array}$

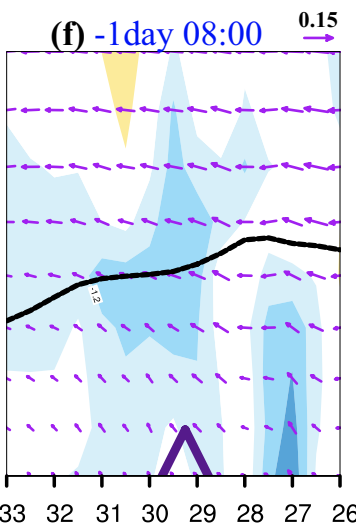

(j) 0day 08:00 $\stackrel{\mathbf{0 . 1 5}}{\rightarrow}$

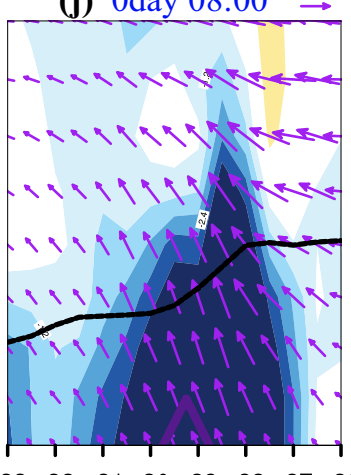

$\begin{array}{llllllll}33 & 32 & 31 & 30 & 29 & 28 & 27 & 26\end{array}$

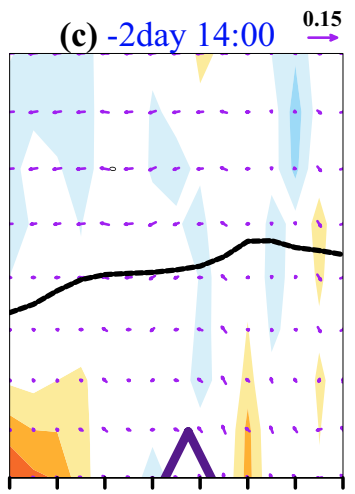

$\begin{array}{llllllll}33 & 32 & 31 & 30 & 29 & 28 & 27 & 26\end{array}$

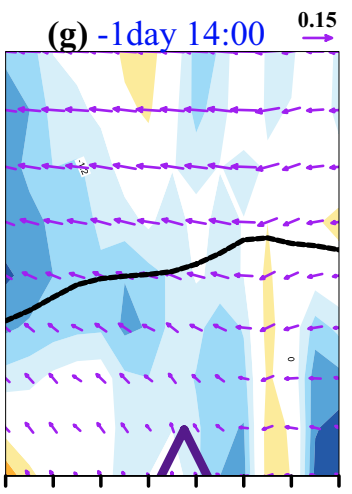

$\begin{array}{llllllll}33 & 32 & 31 & 30 & 29 & 28 & 27 & 26\end{array}$

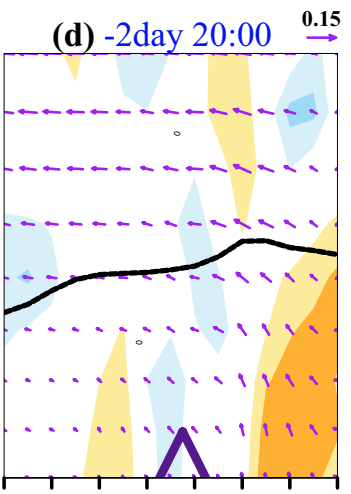

$\begin{array}{llllllll}33 & 32 & 31 & 30 & 29 & 28 & 27 & 26\end{array}$

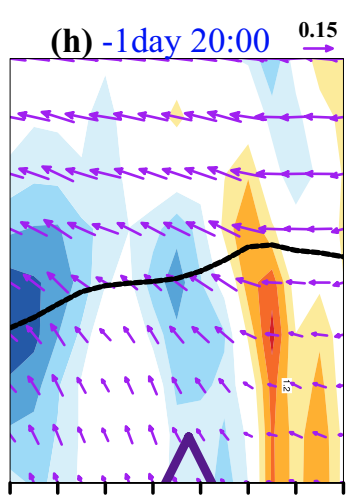

(k) 0day 14:00 $\stackrel{\mathbf{0 . 1 5}}{\rightarrow}$

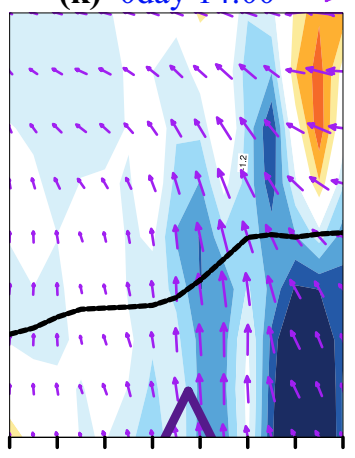

(l) 0day 20:00 $\stackrel{\mathbf{0 . 1 5}}{\rightarrow}$

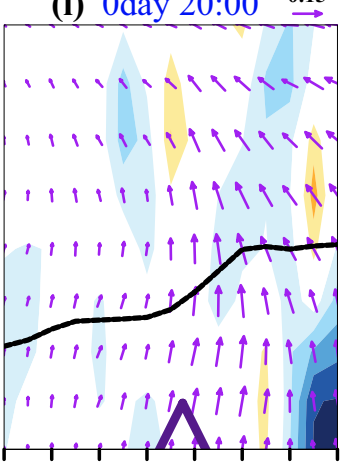

$\begin{array}{llllllll}33 & 32 & 31 & 30 & 29 & 28 & 27 & 26\end{array}$

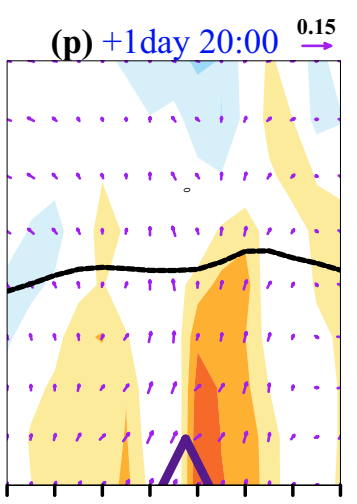

(o) +1 day 14:00 $\stackrel{\mathbf{0 . 1 5}}{\rightarrow}$

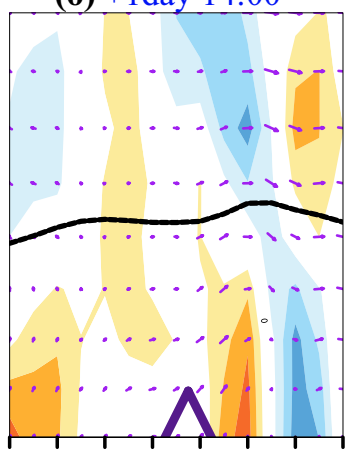

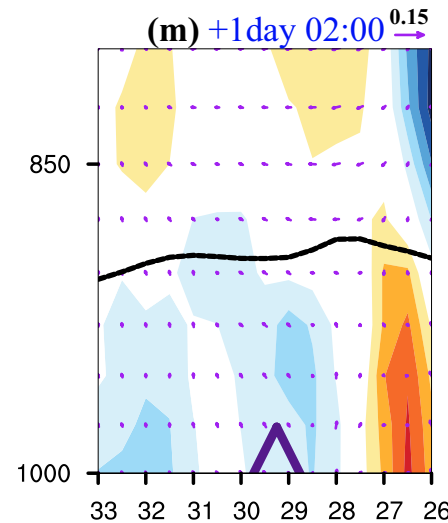

(n) +1 day 08:00 $\stackrel{\mathbf{0 . 1 5}}{\rightarrow}$

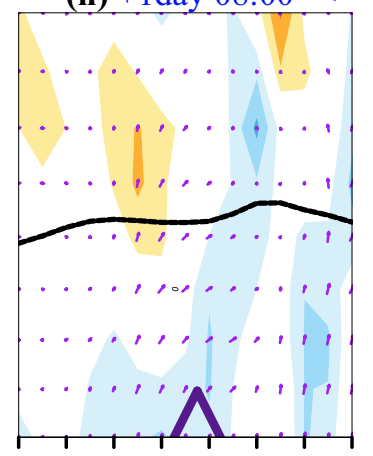

$\begin{array}{llllllll}33 & 32 & 31 & 30 & 29 & 28 & 27 & 26\end{array}$ 
4Fig. 10 The vertical cross sections of the water vapor transport (vectors; $\left.10^{-7} \mathrm{~g} /\left(\mathrm{hPa}^{*} \mathrm{~m} * \mathrm{~s}\right)\right)$ and the divergence of the water vapor transport (shadings; $10^{-12} \mathrm{~g} /\left(\mathrm{hPa}^{*} \mathrm{~m}^{-2 *} \mathrm{~s}\right)$ ) against PC2 over Kuroshio SST front during the winters of 1979-2016 in CFSR data at 02:00 LT, 08:00 LT, 14:00 LT, and 20:00 LT respectively. a-p Are the regressions that PC2 lead 2 days, 1 day, 0 day and -1 day respectively. All shaded values exceed $95 \%$ confidence level

meridional gradient, $\theta_{\mathrm{z}}$ and $Q$ are the static stability and diabatic heating, respectively. The complete form of the vorticity tendency equation is widely adopted to analyze the vorticity evolution in midlatitudes (Liu et al. 2004, 2013; Wu et al. 2009; Ren et al. 2015; Shang et al. 2019). A scaling analysis (Liu et al. 2001; Wu et al. 2009) shows that Eq. (2) can be simplified as:

$\frac{\partial \zeta}{\partial \mathrm{t}} \propto \frac{\mathrm{f}+\zeta}{\theta_{\mathrm{z}}} \frac{\partial Q_{L H}}{\partial \mathrm{z}}$

where $Q_{L H}$ represents the latent heating. The relationship between the vorticity and latent heating indicates that the surface positive vorticity anomaly and the associated cyclonic circulation appear under the latent heat heating caused by the precipitation. Therefore, it is suggested that the precipitation and the local circulation are closely coupled with one another over the Kuroshio SST front.

To investigate the connections relating the local circulation and precipitation, we quantified the surface vorticity anomaly caused by the precipitation anomaly based on Eq. (3). Firstly, the latent heating released by the precipitation anomaly is calculated according to the regression precipitation anomaly. Thus, we obtain the low-level vorticity generated by the precipitation anomaly within the PBL below the maximum latent heating level. The patterns and the high-frequency variations of the vorticity anomaly calculated by Eq. (3) (Fig. 11e-h) are generally consistent with the regression of the vorticity anomaly on PC2 (Fig. 11a-d). The vorticity anomaly due to the precipitation anomaly contributes more than $50 \%$ of the total regression vorticity anomaly over the Kuroshio SST front and its warm side. The ERA5 hourly regression surface vorticity results are consistent with CFSR data. However, there are still some difference between the top panels and the bottom panels in Fig. 11, especially in the coastal regions and marginal seas. These differences are caused by other terms in the complete form of the vorticity tendency equation except the term of vorticity sources induced by vertical gradients of latent heating. Based on the Eq. (2), the vorticity changes are contributed by the terms of the horizontal advection of relative vorticity, $\beta$ effect, divergence of atmospheric circulation, and vorticity sources induced by horizontal and vertical gradients of diabatic heating. To obtain the relationship between the precipitation and the surface vorticity anomalies caused by the Kuroshio SST front effects, we only calculated the surface vorticity anomaly caused by the precipitation anomaly based on Eq. (3) (the simplified equation based on the scaling analysis). The previous studies have proved that the other term also contributes to the vorticity changes in the midlatitude, such as horizontal advection process (Ren et al. 2015; Shang et al. 2019), the horizontal gradients of the diabatic heating (Liu et al. 2001). However, the dominant term is the vorticity source induced by vertical gradients of diabatic heating.

We further calculated the average precipitation anomaly, vorticity anomaly and vertical velocity anomaly regressions on PC2, from PC2 leading 1 day to lagging 1 day over the Kuroshio (Fig. 12). The results suggest that the three key variables have coordinated phase characteristics. The anomaly of the precipitation, vertical upward motion and the positive vorticity are enhanced from PC2 leading 1 day and reach their peaks at 02:00LT, with PC2 leading 0 day, then weaken gradually until PC2 lagging 1 day. This result further confirms that precipitation is significantly coupled to the local circulation. When the coupled system of HV-WCP events moves into the Kuroshio area, precipitation increases and the vorticity anomaly caused by precipitation increases with the accompanying upward vertical motion anomaly. Analogously, when the coupled system of HV-WCP events moves out of the Kuroshio area, precipitation is weakened, and the vorticity anomaly caused by the precipitation and the accompanying vertical velocity are correspondingly weakened.

Therefore, we hypothesize that the variation of the coupled system of the local circulation and precipitation result from the complement process caused the wind high-frequency variability in the HV-WCP events. The specific mechanism and the dynamical process of the HV-WCP events are described as follows. When the winter monsoon weakens and the vertical mixing is reduced within the PBL, the PBL structure resulting from the thermal effect of the Kuroshio SST front is conducive to the transport of moisture into free the atmosphere and its convergence beyond the top of the PBL. Thus, the precipitation anomaly is generated over the adjacent region of the Kuroshio SST front. The latent heating released by the precipitation occurrence forces the cyclonic anomaly and positive vorticity anomaly within the PBL. The enhanced cyclonic anomaly leads to the increase of upward vertical motion and the southeast wind anomaly over the Kuroshio SST front, prompting more moisture to enter the free atmosphere, thereby further enhancing the precipitation anomaly. In turn, the enhanced precipitation anomaly will again force the cyclonic anomaly and positive vorticity anomaly within the PBL. Thus, there is a complement process between circulation and rainfall related to HV-WCP events, which reaches a peak intensity at 02:00 LT over the Kuroshio SST front. Moreover, due to the southeastward extension 

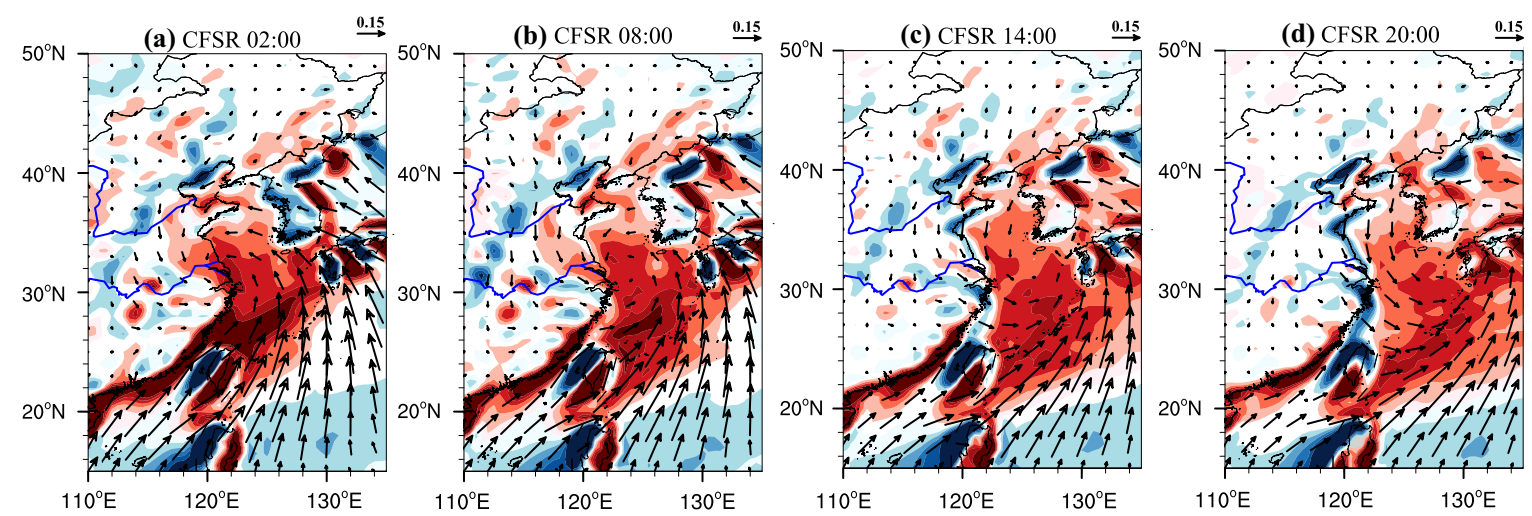

$5.0 e-05$

4.0e-05

3.0e-05

2.0e-05

$1.0 \mathrm{e}-05$

$0.0 \mathrm{e}+05$
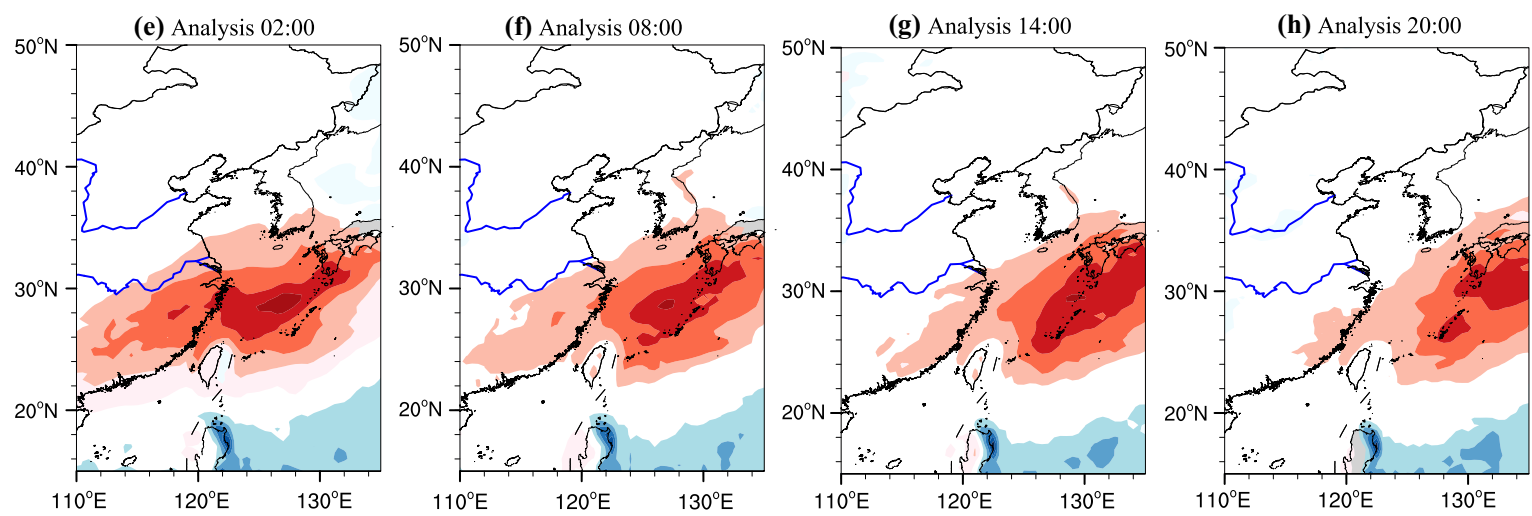

$-1.0 e-05$
$-2.0 e-05$
$-3.0 e-05$
$-4.0 e-05$
$-5.0 e-05$

Fig. 11 The high-frequency variations of the regression wind field (vectors; $\mathrm{m} / \mathrm{s}$ ) and vorticity (shadings; $\mathrm{s}^{-1}$ ) against PC2 over Kuroshio SST front during the winters of 1979-2016 in CFSR data at 02:00 LT, 08:00 LT, 14:00 LT, and 20:00 LT respectively. a-d Are

the vorticity anomalies regressions in CFSR, and the $\mathbf{e}-\mathbf{h}$ are the calculated vorticity anomalies regressions using Eq. (1). All shaded values exceed $95 \%$ confidence level

Fig. 12 The lead-lag regressions of vertical speed $(\mathrm{m} / \mathrm{s})$ (blue line), CFSR vorticity $\left(\mathrm{s}^{-1}\right)$ (solid red line), calculated vorticity $\left(\mathrm{s}^{-1}\right)$ (dotted red line) and precipitation $\left(\mathrm{kg} / \mathrm{m}^{2}\right)$ (green line) against $\mathrm{PC} 2$ averaged over Kuroshio SST front during the winters of 1979-2016 in CFSR at 02:00 LT, 08:00 LT, 14:00 LT, and 20:00 LT respectively

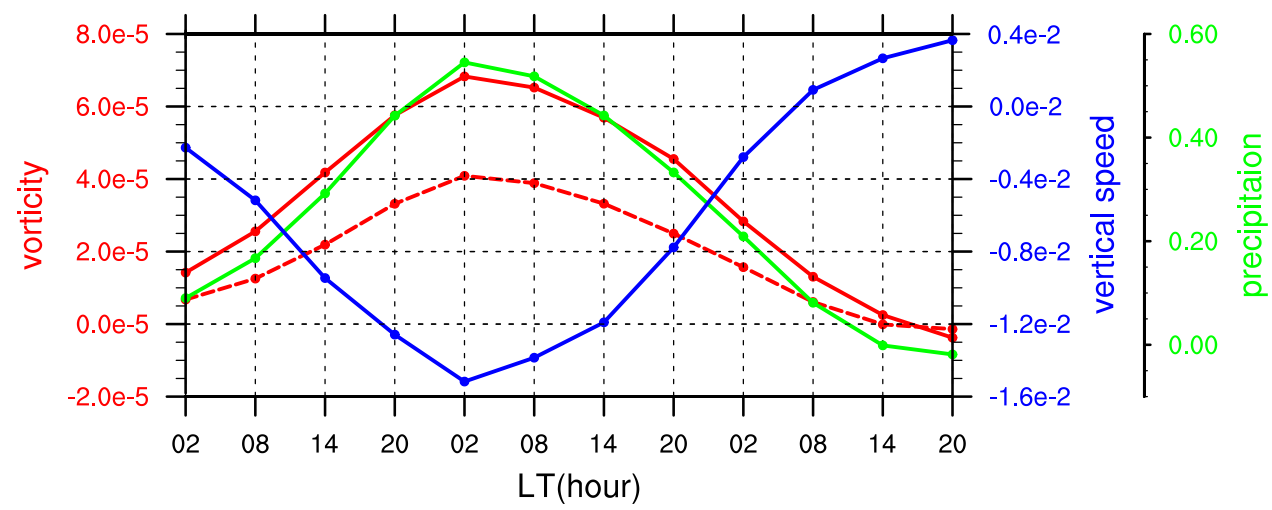

of the background prevailing wind, the coupling system of HV-WCP events gradually moves to the warm flank of the Kuroshio SST front. When the coupling system moves out of SST front, its intensity weakens, since moisture and the PBL conditions are not sufficient to generate more precipitation. Therefore, the coupling system for HV-WCP events vanishes high-frequency when it moves out of Kuroshio SST front region. Significant atmospheric high-frequency variabilities over Kuroshio SST front occurred due to the coupling of the cyclonic circulation and the precipitation.

\subsection{The model simulation results}

However, how much does the existence of the Kuroshio contribute to the complement between circulation and precipitation? Based on the observations, we cannot give a quantitative answer. Therefore, to investigate the complex vertical structure of the MABL responses and the atmospheric high-frequency variation over the Kuroshio SST front, high-resolution simulations of the SST forcing over the ECS were conducted with WRF model. The 
physical parameterization schemes used in the model include the Thompson microphysics scheme (Thompson et al. 2004), the Betts-Miller-Janjic scheme for cumulus parameterization (Janjić 1994, 2000), and the YSU atmospheric boundary layer parameterization scheme for the boundary layer (Hong et al. 2006). The high-resolution CFSR data are used as the lateral boundary conditions and initial field for the WRF simulation. The model domain is $20.0-37.0^{\circ} \mathrm{N}, 118.0-140.0^{\circ} \mathrm{E}$, with a relatively high horizontal resolution of $50 \mathrm{~km}$ and the 28 sigma levels in the vertical. The model output data is available at 6 -hr intervals. The simulations are integrated during the wintertime of 2002-2003 (from the December 1st, 2002 to February 28th, 2003), when the Kuroshio SST front was relatively active.

Following the method of $\mathrm{Xu}$ and $\mathrm{Xu}$ (2015), we designed two experiments to investigate the SST front effects on the HV-WCP events. One is the control (CTL) run forced by the observed SST and the other is the smoothed SST (SmSST) run, in which the SST field is heavily smoothed by applying a two-dimensional 9-point averaging 100 times to decrease the SST gradient and remove the associated Kuroshio SST front. The results of the SmSST run are regarded as the atmospheric response without the influence of the Kuroshio SST front. Therefore, the difference between the CTL run and SmSST run can be considered as the contribution of the Kuroshio SST front. Figure 13 shows the difference results between CTL and SmSST runs. The level 5 HV-WCP events occur 12 times in both CTL and SmSST runs, but the intensity of level 5 HV-WCP events is considerably different. Compared to CTL run, the mean intensity and maximum intensity of level $5 \mathrm{HV}$-WCP events are reduced by 0.22 and 0.51, respectively, in the SmSST run. As for the key process for HV-WCP events, the upward vertical motion in the SmSST run the positive vorticity and the precipitation anomaly decreases by more than $50 \%$ of the corresponding variations in the CTL run over the Kuroshio SST front and its warm flank. Especially for the positive vorticity anomaly, the average vorticity over the Kuroshio SST front and its warm flank of the CTL run are approximately 8 times those of the SmSST run. Therefore, the Kuroshio SST front plays an important role in the HVWCP events over the Kuroshio SST front and its warm flank. It contributes more than $50 \%$ of the local circulation and precipitation anomaly to enhance the complement of the HV-WCP events. When the coupled system is above the Kuroshio SST front, then the precipitation, the associated cyclonic anomaly and the upward vertical motion anomaly increase simultaneously. The complement of the HV-WCP events is reduced when the coupled system moves out of the Kuroshio SST front area.

\section{Summary and discussion}

We conducted a long-term analysis of atmospheric variations during wintertime, and we found that variabilities in significant high-frequency events of the surface wind field are coupled with large-scale precipitation anomalies over the Kuroshio SST front region. Specifically, from 02:00 LT to 20:00 LT on the peak day with the dominant diurnal variabilities, the HV-WCP events have the features that the wind direction changes from southerly anomaly into northwest anomaly, accompanied with increases in wind speed and coupled precipitation which are gradually decreasing. The intensity of the high-frequency wind variations are gradually reduced with increasing geopotential height, and almost disappear in middle and high troposphere levels. Therefore, the diurnal variability in HV-WCP events can be distinguished from the sea-land breeze based on the obvious baroclinic structure. Furthermore, the large-scale circulation conditions have been proven able to sustain the HV-WCP events, with the declining upstream monsoon and the weakening vertical mixing within the PBL.

Due to the weakened winter monsoon, the warm and humid air movements are enhanced due to transport from the warm pool to the cold side of Kuroshio SST front. Therefore, water vapor becomes more abundant over Kuroshio SST frontal area. Meanwhile, the weakening PBL vertical mixing prompts the PBL distribution over the Kuroshio to be no longer uniform as before. Resulting from PBL height increases over the warm flank of the SST front but decreases over the cold side because of the Kuroshio SST front thermal effect, the significant PBL height gradient occurs over the Kuroshio SST front when the MABL stability weakened. Therefore, the enhanced moisture and the simultaneously developing PBL height gradient are able to generate the transport of plentiful water vapor from the PBL to the free atmosphere, bringing about the precipitation anomaly over Kuroshio SST frontal area. Based on a diagnosis of results from the complete form of the vorticity equation, the latent heat release caused by precipitation is able to force the positive vorticity and cyclonic circulation within the PBL. The generation of a cyclonic circulation leads to an increase in upward vertical motion over the Kuroshio SST frontal area, prompting more water vapor to enter the free atmosphere, thereby again further enhancing the precipitation anomaly. This complement process for HV-WCP events reaches a peak over the Kuroshio SST front at early morning on the peak day. Thus, all the related processes, the precipitation anomaly, vorticity anomaly and vertical velocity anomaly, reach their maximum strength at this time (Fig. 14).

By quantifying the results of the CTL and SmSST runs using the WRF simulations, we infer that the presence of the Kuroshio SST front is an essential requirement 


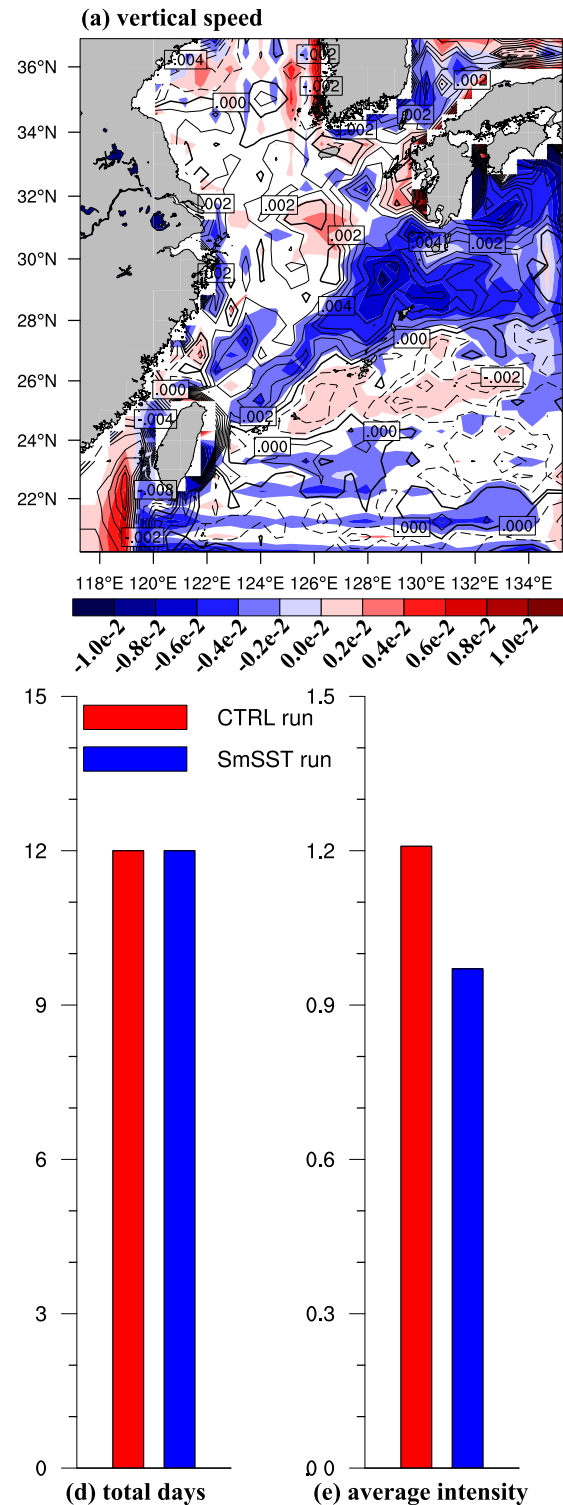

(b) vorticity

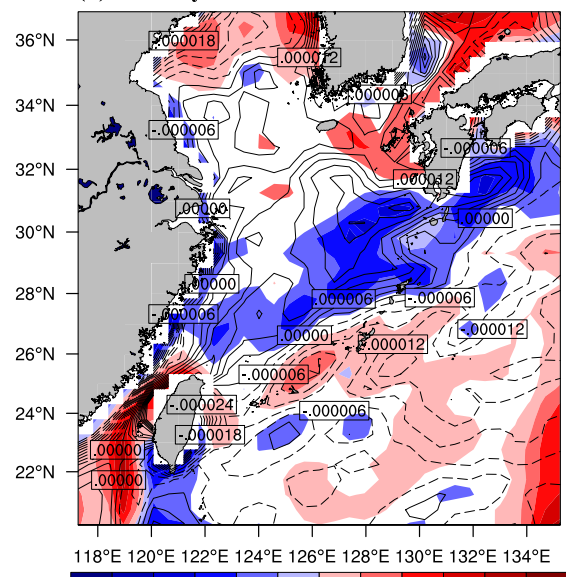

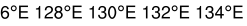

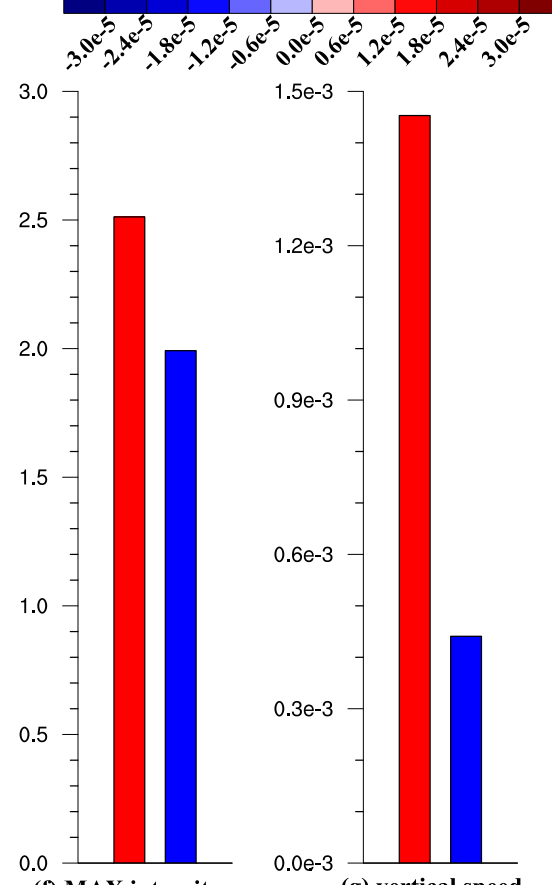

(f) MAX intensity

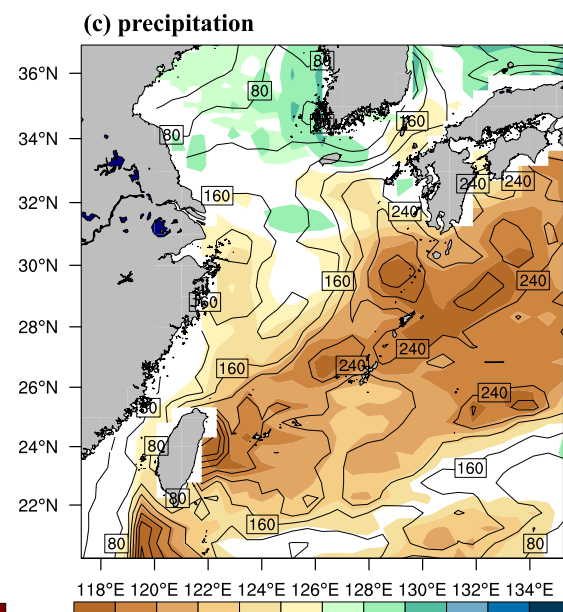

$118^{\circ} \mathrm{E} 120^{\circ} \mathrm{E} 122^{\circ} \mathrm{E} 124^{\circ} \mathrm{E} 126^{\circ} \mathrm{E} 128^{\circ} \mathrm{E} 130^{\circ} \mathrm{E} 132^{\circ} \mathrm{E} 134^{\circ} \mathrm{E}$

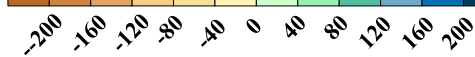

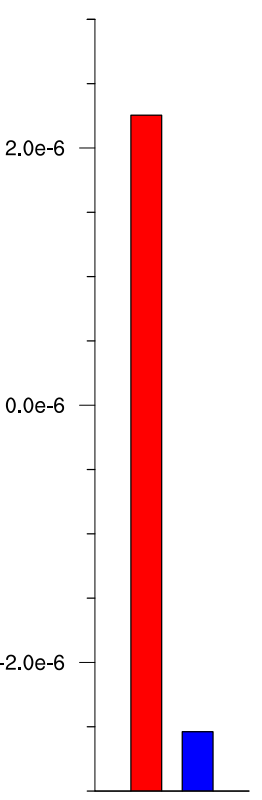

(h) vorticity

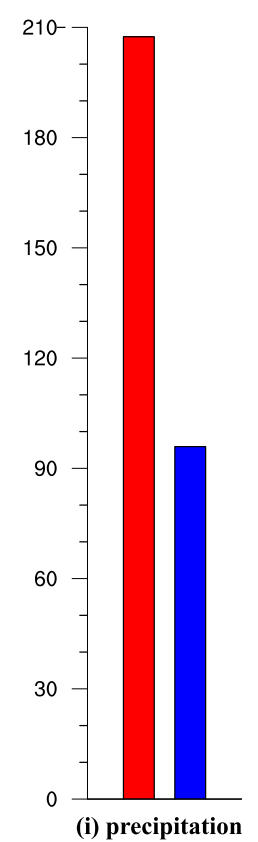

Fig. 13 The vertical speed (m/s) (a), vorticity $\left(\mathrm{s}^{-1}\right)(\mathbf{b})$ and accumulated total grid scale precipitation $(\mathrm{mm})(\mathbf{c})$ of the HV-WCP events over Kuroshio SST front during the winter of 2002-2003 in WRF model. The shadings are the difference of SmSST and CTRL runs, the contours are simulations of the CTRL run. $\mathbf{d}-\mathbf{i}$ Are comparison

for the HV-WCP events. Therefore, the intensity of the complement between wind convergence and precipitation reaches peak intensity over the Kuroshio SST front. Due to the southeastward extension of the background winter monsoon, the entire coupled system moves to the warm side of Kuroshio SST front gradually. When the HV-WCP events move out of the Kuroshio SST frontal area, their intensity weakens since PBL conditions and related water vapor transports are not conducive to generating more precipitation. Therefore, the coupled HV-WCP events vanish quickly when moving out of Kuroshio SST frontal areas. results over Kuroshio SST front of HV-WCP total days, HV-WCP average intensity, HV-WCP maximum intensity, vertical speed, vorticity and precipitation, respectively. All shaded values exceed $95 \%$ confidence level

We have discussed briefly this hypothesis there and the specific mechanism of this decaying process will be investigated detailed in further studies. The two processes of the HV-WCP events take approximately 1-3 days, which associated with the moving atmospheric systems.

In winter while over Kuroshio SST frontal areas, significant HV-WCP events are generated by the coupling of the cyclonic circulation and the precipitation. This process brings about significant rainfall anomalies over southeast China, ECS, YS and Japan. Therefore, the HV-WCP events have significant climate effects on the precipitation 


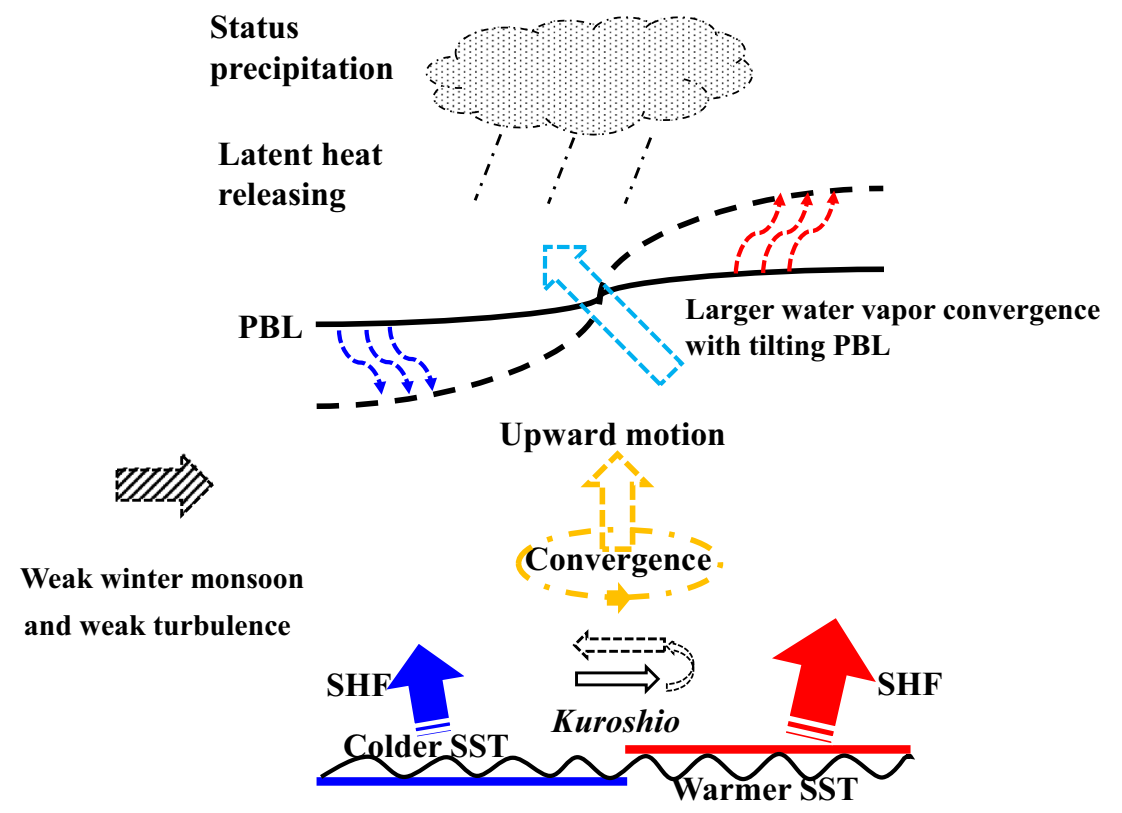

Fig. 14 The schematic diagram of the Kuroshio SST front effects on the circulation and precipitation. The solid blue and solid red lines represent the cold side and the warm side of the Kuroshio SST front, respectively. The upward solid blue arrow and the upward solid red arrow represent the sensible heat flux (SHF) over the cold side and warm side of the Kuroshio SST front, respectively. The wavy black line on the bottom represents the SST over Kuroshio SST front. The rightward dotted black arrow represents the weak winter monsoon. When the winter monsoon weakens, the uniform PBL structure (solid curving black line) changes into stratus with significant PBL

anomalies and its high-frequency variability over southeastern China and the adjacent ocean areas of the ECS. Investigation of this process may give new insight into high-frequency variability and climate change and the associated future predictions over East Asia. Furthermore, although both the Kuroshio and Gulf Stream are characterized the essential air-sea interaction areas with large horizontal SST gradients over North Pacific and North Atlantic, Chen et al. (2019b) have proved there are still obvious differences between Kuroshio region and Gulf Stream, where a warmer climate intensifies the upper-layer Kuroshio but the slowdown of the Gulf Stream. Therefore, whether these characteristics and climate effects, related to the atmospheric high-frequency variability, are still generally consistent over other SST front regions (like the Gulf Stream) needs additional investigation.

We mainly used the CFSR data to analysis the atmospheric high-frequency variabilities over the Kuroshio SST front, which are available at 6-h intervals. In this study, CFSR data can describe the daily variation characteristics to a certain extent, but lack more accurate high-frequency gradient (dotted curving black line). In addition, the westward wind anomalies appear, bringing more moisture from the PBL into the free atmosphere (dotted cyan arrow overlaid PBL), generating the stratus precipitation anomaly (cloud diagram) over the Kuroshio SST front. The latent heat release due to precipitation causes the cyclonic circulation anomaly (orange dotted circle) and the upward vertical motion (upward orange dotted arrow), which increases the rainfall again. The surface wind direction transforms from northwest (rightward solid black arrow over Kuroshio SST front) to southeast (leftward dotted black arrow over Kuroshio SST front)

variation characteristics, such as the wind variations from 20:00 LT to the next day. To ensure the accuracy of the results, we also considered more datasets with higher temporal resolution. Most other datasets give similar results during the same time period. For instance, the highfrequency precipitation variations of TRMM (Tropical Rainfall Measuring Mission) have similar characteristics as CFSR data over the Kuroshio SST frontal area. The high-frequency variability characteristics of near-surface wind field can be recognized in mooring data. Furthermore, we used the ERA5 hourly data from 1979 to 2016 to support more detailed high-frequency revolution. The results (Fig. 6, Figs. S4-S8) validate the characteristics and specific mechanism of HV-WCP events in CFSR results. Thus, the 6-hourly CFSR data are sufficient to obtain the dominant atmospheric high-frequency variabilities over the key area of interest. Furthermore, the CFSR data showed the consistent high-frequency STDs of wind speed and wind direction with CCMP analysis wind product over Kuroshio SST front. Therefore, CFSR data are used as the main dataset in this study, and the ERA5 

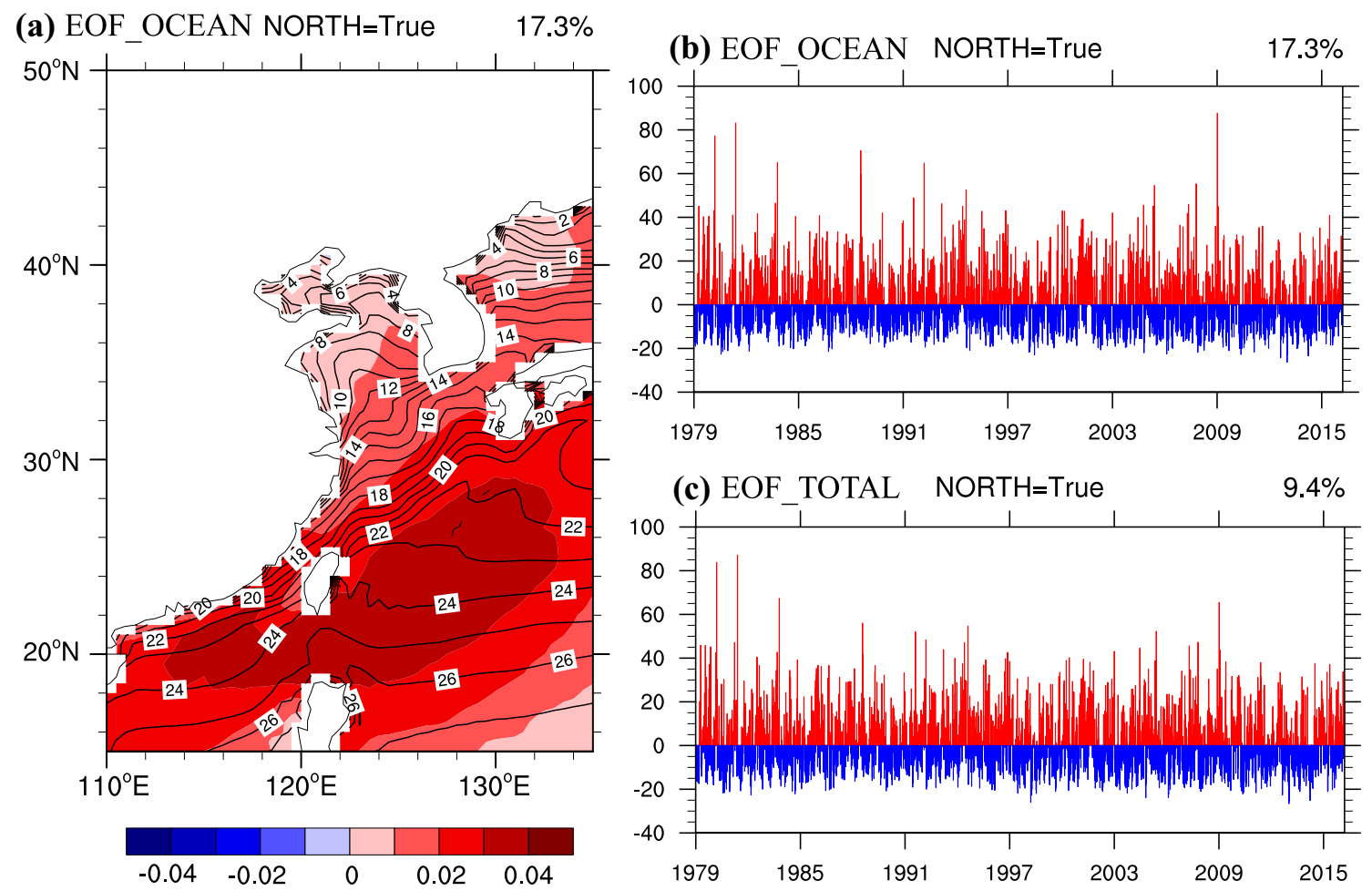

Fig. 15 The a first modes of EOF analysis (shadings) on wind high-frequency variabilities and the SST (contours; ${ }^{\circ} \mathrm{C}$ ) over the region $15^{\circ} \mathrm{N}-50^{\circ}$ $\mathrm{N}, 110^{\circ} \mathrm{E}-135^{\circ} \mathrm{E}$ during the winters of 1979-2016. b Shows the corresponding PC time series of $\mathbf{a}$ and $\mathbf{c}$ is same as the Fig. $2 \mathrm{~d}$

hourly data are used to support CFSR results and support more detailed high-frequency revolution.

In this study, the most important statistical method is rotated EOF analysis. However, the results show that the first two EOF modes (PC1, PC2) each account for less than $10 \%$ of the total variance. Thus, we have considered the less variance contributions for several reasons. Firstly, the dataset used to conduct the EOF analysis contains quite a long time period, from 1979 to 2016 (3330 days; 3330*4 times). Moreover, the results of the EOF analysis are strongly dependent on the analysis regions. Therefore, the high-frequency variabilities of surface wind over land influence the variance contribution and distribution of every EOF mode. To compare with previous studies (Chen et al. 2009, 2013; Du et al. 2012; Du and Rotunno 2014, 2018), we conducted EOF analysis over both the ocean and land in Fig. 2. However, in this study, the key area on which we focus is the Kuroshio SST frontal area. Therefore, we calculated the rotated EOF results just over the ocean to eliminate the land effects on the EOF analysis. It is obvious that the variance contribution of EOF1 increases significantly to $17.3 \%$ in this situation (Fig. 15a). Moreover, the time series of the corresponding principal component is basically the same as the PC2 of the previous rotated EOF over the total land and ocean regions (Fig. 15b, c). The correlation between the two PCs is up to 0.946 , implying that the corresponding regression results obtained by the two PCs are almost same over the Kuroshio SST frontal area. Furthermore, the ERA5 hourly results are consistent with CFSR data (Fig. S9).

To quantify the Kuroshio contributions, we designed control and sensitivity experiments in Sect. 4. The sensitivity experiments changed the intensity of the Kuroshio SST front by reconstructing the SST field. Besides the SmSST run, we also designed numerous experiments with increasing SST frontal intensity (IncSST run). However, the differences between the IncSST runs and the CTL run are less pronounced than the differences between the SmSST and CTL runs. Results suggest that the Kuroshio SST frontal intensity of the CTL run, which is equal to the value of the observations, is sufficient to force the required PBL height gradient to activate the HV-WCP events. The additional increased intensity of SST front experiments cannot provide significant additional enhancement to the PBL height gradient and the related moisture transports. Thus, the effects of the SST front cannot continue to intensify, with increasing frontal intensity. However, the specific dynamical relationships between the frontal intensity and the HV-WCP events need additional investigation.

Acknowledgements This work was supported by the National Key Program for Developing Basic Science (Grant nos. 2016YFA0600303 $\&$ 2018YFC1505900), the National Natural Science Foundation of China (Grant nos. 41675064 \& 41621005 \& 41330420 \& 41675067 
\& 41875086), the Jiangsu Province Science Foundation (Grant no. BK2020020170). This work was jointly supported by the Jiangsu Collaborative Innovation Center of Climate Change and Key Laboratory Project Foundation (Grant No. KLME1501). Support from Canada's Aquatic Climate Change Adaptation Services Program is also acknowledged. Thanks to the support of the Jiangsu provincial Innovation Center for climate change. The CFSR 6-hourly products and the CFSv2 6-hourly products used in this study were obtained from http://rda. ucar.edu/datasets/ds093.0/ and https://rda.ucar.edu/datasets/ds094.0/, respectively. The CCMP Version-2.0 vector wind analyses are produced by Remote Sensing Systems. Data are available at https://www. remss.com. The ERA5 hourly data are available through ECWMF's Climate Data Store at https://cds.climate.copernicus.eu/cdsapp\#!/datas et/reanalysis-era5-single-levels?tab=form and https://cds.climate.coper nicus.eu/cdsapp\#!/dataset/reanalysis-era5-pressure-levels?tab=form.

Open Access This article is licensed under a Creative Commons Attribution 4.0 International License, which permits use, sharing, adaptation, distribution and reproduction in any medium or format, as long as you give appropriate credit to the original author(s) and the source, provide a link to the Creative Commons licence, and indicate if changes were made. The images or other third party material in this article are included in the article's Creative Commons licence, unless indicated otherwise in a credit line to the material. If material is not included in the article's Creative Commons licence and your intended use is not permitted by statutory regulation or exceeds the permitted use, you will need to obtain permission directly from the copyright holder. To view a copy of this licence, visit http://creativecommons.org/licenses/by/4.0/.

\section{References}

Bai H, Hu H, Yang X-Q, Ren X, Xu H, Liu G (2019) Modeled MABL Responses to the Winter Kuroshio SST Front in the East China Sea and Yellow Sea. J Geophys Res Atmos 124:6069-6092. https ://doi.org/10.1029/2018jd029570

Bao X, Zhang F, Sun J (2011) Diurnal variations of warm-season precipitation East of the Tibetan Plateau over China. Mon Weather Rev 139(9):2790-2810. https://doi.org/10.1175/MWR-D-1100006.1

Barnston AG, Livezey RE (1987) Classification, seasonality and persistence of low-frequency atmospheric circulation patterns. Mon Weather Rev 115:1083-1126. https://doi.org/10.1175/MWR-D11-00006.1

Blackadar AK (1957) Boundary layer wind maxima and their significance for the growth of nocturnal inversions. B Am Meteorol Soc 38:283-290. https://doi.org/10.1175/15200442(1996)009<2802:DVOCCA > 2.0.CO;2

Blackmon ML (1976) A climatological spectral study of the $500 \mathrm{mb}$ geopotential height of the Northern Hemisphere. J Atmos Sci 33:1607-1623. https://doi.org/10.1175/15200469(1976)033<1607:Acssot>2.0.Co;2

Bonner WD, Paegle J (1970) Diurnal variations in boundary layer winds over the south-central United States in summer. Mon Weather Rev 98:735-744. https://doi.org/10.1175/15200493(1970)098<0735:DVIBLW>2.3.CO;2

Bryan FO, Tomas R, Dennis JM, Chelton DB, Loeb NG, McClean JL (2010) Frontal scale air-sea interaction in high-resolution coupled climate models. J Clim 23:6277-6291. https://doi. org/10.1175/2010JCLI3665.1

Carillo A, Ruti P, Navarra A (2000) Storm tracks and zonal mean flow variability: a comparison between observed and simulated data. Clim Dyn 16:219-228. https://doi.org/10.1007/s003820050015
Carvalho D, Rocha A, Gómez-Gesteira M, Santos CS (2014) Sensitivity of the WRF model wind simulation and wind energy production estimates to planetary boundary layer parameterizations for onshore and offshore areas in the Iberian Peninsula. Appl Energy 135:234-246. https://doi.org/10.1016/j.apenergy.2014.08.082

Chelton DB, Xie S-P (2010) Coupled ocean-atmosphere interaction at oceanic mesoscales. Oceanography 23:52-69. https://doi. org/10.5670/oceanog.2010.05

Chelton DB, Schlax MG, Freilich MH, Milliff RF (2004) Satellite measurements reveal persistent small-scale features in ocean winds. Science 303:978-983. https://doi.org/10.1126/scien ce.1091901

Chen G et al (2015) Toward improved forecasts of sea-breeze horizontal convective rolls at super high resolutions. Part I: configuration and verification of a Down-Scaling Simulation System (DS3). Mon Weather Rev 143:1849-1872. https://doi.org/10.1175/ MWR-D-14-00212.1

Chen G, Sha W, Iwasaki T (2009) Diurnal variation of precipitation over southeastern China: 2. Impact of the diurnal monsoon variability. J Geophys Res Atmos. https://doi.org/10.1029/2009J D012181

Chen G, Sha W, Sawada M, Iwasaki T (2013) Influence of summer monsoon diurnal cycle on moisture transport and precipitation over eastern China. J Geophys Res Atmos 118:3163-3177. https ://doi.org/10.1002/jgrd.50337

Chen Q, Hu H, Ren X, Yang XQ (2019a) Numerical simulation of midlatitude upper-level zonal wind response to the change of north Pacific subtropical front strength. J Geophys Res Atmos 124:4891-4912. https://doi.org/10.1029/2018JD029589

Chen C, Wang G, Xie SP, Liu W (2019b) Why does global warming weaken the Gulf Stream but intensify the Kuroshio? J Clim 32:7437-7451. https://doi.org/10.1175/JCLI-D-18-0895.1

Ciesielski PE, Johnson RH (2008) Diurnal cycle of surface flows during 2004 NAME and comparison to model reanalysis. J Clim 21:3890-3913. https://doi.org/10.1175/2008JCLI2206.1

Dai A, Deser C (1999) Diurnal and semidiurnal variations in global surface wind and divergence fields. J Geophys Res Atmos 104:31109-31125. https://doi.org/10.1029/1999JD900927

Dai A, Trenberth KE (2004) The diurnal cycle and its depiction in the community climate system model. J Clim 17:930-951. https://doi.org/10.1175/1520-0442(2004)017<0930:TDCAI $\mathrm{D}>2.0 . \mathrm{CO} ; 2$

Du Y, Rotunno R (2014) A simple analytical model of the nocturnal low-level jet over the Great Plains of the United States. J Atmos Sci 71:3674-3683. https://doi.org/10.1175/jas-d-14-0060.1

Du Y, Rotunno R (2015) Thermally driven diurnally periodic wind signals off the east coast of China. J Atmos Sci 72:2806-2821. https://doi.org/10.1175/jas-d-14-0339.1

Du Y, Rotunno R (2018) Diurnal cycle of rainfall and winds near the south coast of China. J Atmos Sci 75:2065-2082. https://doi. org/10.1175/jas-d-14-0339.1

Du Y, Zhang Q, Ying Y, Yang Y (2012) Characteristics of low-level jets in Shanghai during the 2008-2009 warm seasons as inferred from wind profiler radar data. J Meteorol Soc Jpn Ser II 90:891903. https://doi.org/10.2151/jmsj.2012-603

Ertel H (1942) Ein neuer hydrodynamischer Wirbelsatz. Met Z 59:277_ 281. https://doi.org/10.1007/BF01475602

Feliks Y, Ghil M, Simonnet E (2004) Low-frequency variability in the midlatitude atmosphere induced by an oceanic thermal front. J Atmos Sci 61:961-981. https://doi.org/10.1175/15200469(2004)061<0961:Lvitma>2.0.Co;2

Feliks Y, Ghil M, Simonnet E (2007) Low-frequency variability in the midlatitude baroclinic atmosphere induced by an oceanic thermal front. J Atmos Sci 64:97-116. https://doi.org/10.1175/jas3780.1

Fujinami H, Yasunari T (2001) The seasonal and intraseasonal variability of diurnal cloud activity over the Tibetan Plateau. J 
Meteorol Soc Jpn Ser II 79:1207-1227. https://doi.org/10.2151/ jmsj.79.1207

Garreaud R, Wallace JM (1997) The Diurnal March of Convective Cloudiness over the Americas. Mon Weather Rev 125:3157-3171. https://doi.org/10.1175/15200493(1997)125<3157:Tdmocc > 2.0.Co

Guan W, Hu H, Ren X, Yang XQ (2019) Subseasonal zonal variability of the western Pacific subtropical high in summer: climate impacts and underlying mechanisms. Clim Dyn 53:3325-3344. https://doi.org/10.1007/s00382-019-04705-4

Hamilton K (1980) The geographical distribution of the solar semidiurnal surface pressure oscillation. J Geophys Res Oceans 85:1945-1949. https://doi.org/10.1029/jc085ic04p01945

Hashizume $\mathrm{H}$ et al. (2002) Direct observations of atmospheric boundary layer response to SST variations associated with tropical instability waves over the eastern equatorial Pacific. J Clim 15:3379-3393. https://doi.org/10.1175/15200442(2002)015<3379:DOOABL > 2.0.CO;2

Hayes S, McPhaden M, Wallace J (1989) The influence of sea-surface temperature on surface wind in the eastern equatorial Pacific: weekly to monthly variability. J Clim 2:1500-1506. https:// doi.org/10.1175/1520-0442(1989)002<1500:tiosst>2.0.co;2

Higgins R, Yao Y, Yarosh E, Janowiak JE, Mo K (1997) Influence of the Great Plains low-level jet on summertime precipitation and moisture transport over the central United States. J Clim 10:481-507. https://doi.org/10.1175/15200442(1997)010<0481:IOTGPL > 2.0.CO;2

Hirata H, Kawamura R, Yoshioka MK, Nonaka M, Tsuboki K (2019) Key role of the Kuroshio Current in the formation of frontal structure of an extratropical cyclone associated with heavy precipitation. J Geophys Res Atmos 124:6143-6156. https://doi. org/10.1029/2018JD029578

Holton JR (1967) The diurnal boundary layer wind oscillation above sloping terrain. Tellus 19:200-205. https://doi.org/10.3402/tellu sa.v19i2.9766

Hong S-Y, Noh Y, Dudhia J (2006) A new vertical diffusion package with an explicit treatment of entrainment processes. Mon Weather Rev 134:2318-2341. https://doi.org/10.1175/MWR31 99.1

Hoskins BJ, Hodges KI (2002) New perspectives on the northern hemisphere winter storm tracks. J Atmos Sci 59:1041-1061. https:// doi.org/10.1175/1520-0469(2002)059<1041:Npotnh >2.0.Co;2

Hoskins BJ, McIntyre ME, Robertson AW (1985) On the use and significance of isentropic potential vorticity maps. Q J R Meteorol Soc 111:877-946. https://doi.org/10.1002/qj.49711147002

Huang WR, Chan JC, Wang SY (2010) A planetary-scale land-sea breeze circulation in East Asia and the western North Pacific. Q J R Meteorol Soc 136:1543-1553. https://doi.org/10.1002/qj.663

Janjić ZI (1994) The step-mountain eta coordinate model: further developments of the convection, viscous sublayer, and turbulence closure schemes. Mon Weather Rev 122:927-945. https:// doi.org/10.1175/1520-0493(1994)1222.0.CO;2

Janjić ZI (2000) Comments on "Development and evaluation of a convection scheme for use in climate models". J Atmos Sci 57:3686-3686. https://doi.org/10.1175/1520-0469(2000)05760 ;3686:CODAEO62;2.0.CO;2

Kikuchi K, Wang B (2008) Diurnal precipitation regimes in the global tropics. J Clim 21(11):2680-2696. https://doi.org/10.1175/2007J CLI2051.1

Kraus EB (1963) The diurnal precipitation change over the sea. J Atmos Sci 20:551-556. https://doi.org/10.1175/15200469(1963)020<0551:TDPCOT>2.0.CO;2

Krishnamurti T, Kishtawal C, Shin D, Williford CE (2000) Improving tropical precipitation forecasts from a multianalysis superensemble. J Clim 13:4217-4227. https://doi. org/10.1175/1520-0442(2000)0132.0.CO;2
Kuwano-Yoshida A, Minobe S, Xie S-P (2010) Precipitation response to the Gulf Stream in an atmospheric GCM. J Clim 23:36763698. https://doi.org/10.1175/2010JCLI3261.1

Li J, Yu R, Zhou T (2008) Seasonal variation of the diurnal cycle of rainfall in southern contiguous China. J Clim 21:6036-6043. https://doi.org/10.1175/2008JCLI2188.1

Lindzen RS, Nigam S (1987) On the role of sea surface temperature gradients in forcing low-level winds and convergence in the tropics. J Atmos Sci 44:2418-2436. https://doi.org/10.1175/15200469(1987)044<2418:OTROSS > 2.0.CO;2

Liu Y, Wu G, Liu H, Liu P (2001) Condensation heating of the Asian summer monsoon and the subtropical anticyclone in the Eastern Hemisphere. Clim Dyn 17:327-338. https://doi. org/10.1007/s003820000117

Liu Y, Wu G, Ren R (2004) Relationship between the subtropical anticyclone and diabatic heating. J Clim 17:682-698. https:// doi.org/10.1175/1520-0442(2004)017<0682:rbtsaa >2.0.co;2

Liu B, Wu G, Mao J, He J (2013) Genesis of the South Asian high and its impact on the Asian summer monsoon onset. J Clim 26:2976-2991. https://doi.org/10.1175/JCLI-D-12-00286.1

Minobe S, Kuwano-Yoshida A, Komori N, Xie S-P, Small RJ (2008) Influence of the Gulf Stream on the troposphere. Nature 452:206-209. https://doi.org/10.1038/nature06690

Nakamura H, Kazmin AS (2003) Decadal changes in the North Pacific oceanic frontal zones as revealed in ship and satellite observations. J Geophys Res Oceans. https://doi. org/10.1029/1999jc000085

Nakamura H, Shimpo A (2004) Seasonal variations in the southern hemisphere storm tracks and jet streams as revealed in a reanalysis dataset. J Clim 17:1828-1844. https://doi. org/10.1175/1520-0442(2004)017<1828:Svitsh>2.0.Co;2

Nakamura H, Lin G, Yamagata T (1997) Decadal climate variability in the North Pacific during the recent decades. B Am Meteorol Soc 78:2215-2226. https://doi.org/10.1175/15200477(1997)078<2215:Dcvitn>2.0.Co;2

Nakamura H, Izumi T, Sampe T (2002) Interannual and decadal modulations recently observed in the Pacific storm track activity and East Asian winter monsoon. J Clim 15:1855-1874. https://doi.org/10.1175/1520-0442(2002)015<1855:Iadmr o> 2.0.Co;2

Nakamura H, Sampe T, Tanimoto Y, Shimpo A (2004) Observed associations among storm tracks, jet streams and midlatitude oceanic fronts. In: Wang C, Xie SP, Carton JA (eds) Earth's climate: the ocean-atmosphere interaction. Geophysical Monograph Series, vol 147. American Geophysical Union, pp 329345. https://doi.org/10.1029/147gm18

Neumann J (1951) Land Breezes and Nocturnal Thunderstorms. J Meteor 8:60-67. https://doi.org/10.1175/1520-0469(1951)0082.0.CO;2

O'Lenic EA, Livezey RE (1988) Practical considerations in the use of rotated principal component analysis (RPCA) in diagnostic studies of upper-air height fields. Mon Weather Rev 116:1682-1689. https://doi.org/10.1175/15200493(1988)116<1682:PCITUO > 2.0.CO;2

Ramage C (1952) Diurnal variation of summer rainfall over east China, Korea and Japan. J Meteorol 9:83-86. https://doi. org/10.1175/1520-0469(1952)0092.0.CO;2

Ren X, Yang D, Yang X-Q (2015) Characteristics and mechanisms of the subseasonal eastward extension of the South Asian high. J Clim 28:6799-6822. https://doi.org/10.1175/jcli-d-14-00682.1

Richman MB (1986) Rotation of principal components. J Climatol 6:293-335. https://doi.org/10.1002/joc.337006030

Richman MB, Lamb PJ (1985) Climatic pattern analysis of three-and seven-day summer rainfall in the central United States: some methodological considerations and a regionalization. J Clim Appl Meteorol 24:1325-1343. https://doi. org/10.1175/1520-0450(1985)0242.0.CO;2 
Saha S et al (2011) NCEP climate forecast system version 2 (CFSv2) 6-hourly products. Research Data Archive at the National Center for Atmospheric Research, Computational and Information Systems Laboratory. https://doi.org/10.5065/D61C1TXF

Saha $\mathrm{S}$ et al (2014) The NCEP climate forecast system version 2. J Clim 27:2185-2208. https://doi.org/10.1175/jcli-d-12-00823.1

Sasaki YN, Minobe S, Asai T, Inatsu M (2012) Influence of the Kuroshio in the East China Sea on the early summer (Baiu) rain. J Clim 25:6627-6645. https://doi.org/10.1175/jclid-11-00727.1

Schneider N, Qiu B (2015) The atmospheric response to weak sea surface temperature fronts. J Atmos Sci 72:3356-3377. https:// doi.org/10.1175/jas-d-14-0212.1

Shang W, Ren X, Huang B, Cubasch U, Yang X-Q (2019) Subseasonal intensity variation of the South Asian high in relationship to diabatic heating: observation and CMIP5 models. Clim Dyn 52:2413-2430. https://doi.org/10.1007/s00382-018-4266-4

Shapiro A, Fedorovich E (2010) Analytical description of a nocturnal low-level jet. Q J R Meteorol Soc 136:1255-1262. https://doi. org/10.1002/qj.628

Shimada T, Kawamura H (2008) Satellite evidence of wintertime atmospheric boundary layer responses to multiple SST fronts in the Japan Sea. Geophys Res Lett. https://doi.org/10.1029/2008g 1035810

Skamarock WC, Klemp JB, Dudhia J, Gill DO, Barker DM, Wang W, Powers JG (2008) A description of the Advanced Research WRF version 3. NCAR Technical note-475 + STR

Skyllingstad ED, Vickers D, Mahrt L, Samelson R (2007) Effects of mesoscale sea-surface temperature fronts on the marine atmospheric boundary layer. Bound Layer Meteorol 123:219-237. https://doi.org/10.1007/s10546-006-9127-8

Small RD et al (2008) Air-sea interaction over ocean fronts and eddies. Dyn Atmos Oceans 45:274-319. https://doi.org/10.1016/j.dynat moce.2008.01.001

Small RJ, Xie S-P, Wang Y (2003) Numerical simulation of atmospheric response to Pacific tropical instability waves. J Clim 16:3723-3741. https://doi.org/10.1175/15200442(2003)016<3723:nsoart>2.0.co;2

Small RJ, Xie S-P, Wang Y, Esbensen SK, Vickers D (2005) Numerical simulation of boundary layer structure and cross-equatorial flow in the eastern Pacific. J Atmos Sci 62:1812-1830. https:// doi.org/10.1175/JAS3433.1

Song Q, Cornillon P, Hara T (2006) Surface wind response to oceanic fronts. J Geophys Res Oceans. https://doi.org/10.1029/2006j $\mathrm{c} 003680$

Sorooshian S, Gao X, Hsu K, Maddox R, Hong Y, Gupta HV, Imam B (2002) Diurnal variability of tropical rainfall retrieved from combined GOES and TRMM satellite information. J Clim 15:9831001. https://doi.org/10.1175/1520-0442(2002)0152.0.CO;2

Sui C, Li X, Lau K (1998) Radiative-convective processes in simulated diurnal variations of tropical oceanic convection. $\mathrm{J}$ Atmos Sci 55:2345-2357. https://doi.org/10.1175/15200469(1998)055<2345:RCPISD > 2.0.CO

Terao T, Islam MN, Hayashi T, Oka T (2006) Nocturnal jet and its effects on early morning rainfall peak over northeastern Bangladesh during the summer monsoon season. Geophys Res Lett. https://doi.org/10.1029/2006gl026156

Thompson G, Rasmussen RM, Manning K (2004) Explicit forecasts of winter precipitation using an improved bulk microphysics scheme. Part I: description and sensitivity analysis. Mon Weather Rev 132:519-542. https://doi.org/10.1175/15200493(2004)132<0519:EFOWPU>2.0.CO;2

Tokinaga $\mathrm{H}$ et al (2006) Atmospheric sounding over the winter Kuroshio extension: effect of surface stability on atmospheric boundary layer structure. Geophys Res Lett. https://doi. org/10.1029/2005GL025102
Tokinaga H, Tanimoto Y, Xie S-P (2005) SST-induced surface wind variations over the Brazil-Malvinas confluence: satellite and in situ observations. J Clim 18:3470-3482. https://doi. org/10.1175/JCLI3485.1

Van de Wiel BJH, Moene AF, Steeneveld GJ, Baas P, Bosveld FC, Holtslag AAM (2010) A conceptual view on inertial oscillations and nocturnal low-level jets. J Atmos Sci 67:2679-2689. https:// doi.org/10.1175/2010JAS3289.1

Wai MK, Welsh PT, Ma W-M (1996) Interaction of secondary circulations with the summer monsoon and diurnal rainfall over Hong Kong. Bound Layer Meteorol 81:123-146. https://doi. org/10.1007/bf00119062

Wallace JM (1975) Diurnal variations in precipitation and thunderstorm frequency over the conterminous United States. Mon Weather Rev 103:406-419. https://doi. org/10.1175/1520-0493(1975)1032.0.CO;2

Wallace JM, Mitchell T, Deser C (1989) The influence of sea-surface temperature on surface wind in the eastern equatorial Pacific: seasonal and interannual variability. J Clim 2:1492-1499. https ://doi.org/10.1175/1520-0442(1989)002<1492:tiosst>2.0.co;2

Wang L, Hu H, Yang X (2019) The atmospheric responses to the intensity variability of subtropical front in the wintertime North Pacific. Clim Dyn 52:5623-5639. https://doi.org/10.1007/s0038 2-018-4468-9

Wolyn PG, Mckee TB (1994) The mountain-plains circulation east of a 2-km-high north-south barrier. Mon Weather Rev 122:1490 1508. https://doi.org/10.1175/2010jas3289.1

Wu G, Liu H-Z (1998) Vertical vorticity development owing to downsliding at slantwise isentropic surface. Dyn Atmos Oceans 27:715-743. https://doi.org/10.1016/s0377-0265(97)00040-7

Wu G, Liu Y, Liu P (1999) The effect of spatially nonuniform heating on the formation and variation of subtropical high. Part I: scale analysis. Acta Meteorol Sin 57:257-263. https://doi. org/10.11676/qxxb1999.025

Wu G, Liu Y, Zhu X, Li W, Ren R, Duan A, Liang X (2009) Multiscale forcing and the formation of subtropical desert and monsoon. Ann Geophys 27:3631-3644. https://doi.org/10.5194/ angeo-27-3631-2009

Xu M, Xu H (2015) Atmospheric responses to Kuroshio SST front in the East China Sea under different prevailing winds in winter and spring. J Clim 28:3191-3211. https://doi.org/10.1175/JCLID-13-00675.1

Xu H, Xu M, Xie S-P, Wang Y (2011) Deep atmospheric response to the spring Kuroshio over the East China Sea. J Clim 24:49594972. https://doi.org/10.1175/JCLI-D-10-05034.1

$\mathrm{Xu} \mathrm{M}, \mathrm{Xu} \mathrm{H}$, Ren H (2018) Influence of Kuroshio SST front in the East China Sea on the climatological evolution of Meiyu rainband. Clim Dyn 50:1243-1266. https://doi.org/10.1007/s0038 2-017-3681-2

Xue M, Luo X, Zhu K, Sun Z, Fei J (2018) The controlling role of boundary layer inertial oscillations in Meiyu frontal precipitation and its diurnal cycles over China. J Geophys Res Atmos 123:5090-5115. https://doi.org/10.1029/2018JD028368

Yang G-Y, Slingo J (2001) The diurnal cycle in the tropics. Mon Weather Rev 129:784-801. https://doi.org/10.1175/15200493(2001)129<0784:tdcitt>2.0.co;2R

Yang S, Smith EA (2006) Mechanisms for diurnal variability of global tropical rainfall observed from TRMM. J Clim 19:5190-5226. https://doi.org/10.1175/JCLI3883.1

Yu R, Xu Y, Zhou T, Li J (2007) Relation between rainfall duration and diurnal variation in the warm season precipitation over central eastern China. Geophys Res Lett. https://doi.org/10.1029/2007a GL030315

Yu R, Zhou T, Xiong A, Zhu Y, Li J (2007) Diurnal variations of summer precipitation over contiguous China. Geophys Res Lett. https ://doi.org/10.1029/2006GL028129 
Yu R, Li J, Chen H (2009) Diurnal variation of surface wind over central eastern China. Clim Dyn 33:1089. https://doi.org/10.1007/ s00382-008-0478-3

Zhou T, Yu R, Chen H, Dai A, Pan Y (2008) Summer precipitation frequency, intensity, and diurnal cycle over China: a comparison of satellite data with rain gauge observations. J Clim 21:3997-4010. https://doi.org/10.1175/2008JCLI2028.1
Publisher's Note Springer Nature remains neutral with regard to jurisdictional claims in published maps and institutional affiliations 